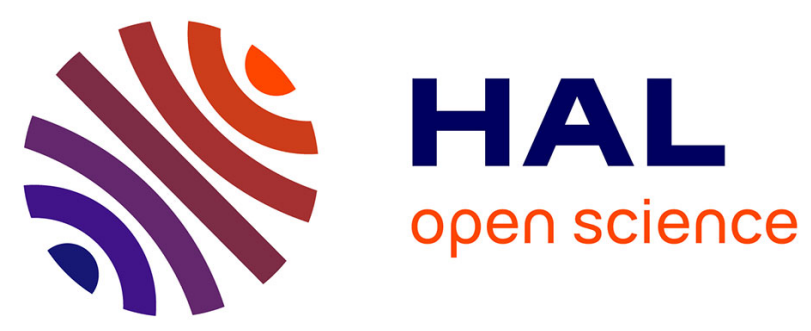

\title{
Aiming strategy optimization for uniform flux distribution in the receiver of a linear Fresnel solar reflector using a multi-objective genetic algorithm
}

Yu Qiu, Ming-Jia Li, Kun Wang, Zhan-Bin Liu, Xiao-Dai Xue

\section{- To cite this version:}

Yu Qiu, Ming-Jia Li, Kun Wang, Zhan-Bin Liu, Xiao-Dai Xue. Aiming strategy optimization for uniform flux distribution in the receiver of a linear Fresnel solar reflector using a multi-objective genetic algorithm. Applied Energy, 2017, 205, pp.1394-1407. 10.1016/j.apenergy.2017.09.092 . hal$01413599 v 3$

\section{HAL Id: hal-01413599 \\ https://hal.science/hal-01413599v3}

Submitted on 17 Nov 2017

HAL is a multi-disciplinary open access archive for the deposit and dissemination of scientific research documents, whether they are published or not. The documents may come from teaching and research institutions in France or abroad, or from public or private research centers.
L'archive ouverte pluridisciplinaire HAL, est destinée au dépôt et à la diffusion de documents scientifiques de niveau recherche, publiés ou non, émanant des établissements d'enseignement et de recherche français ou étrangers, des laboratoires publics ou privés. 


\title{
Aiming strategy optimization for uniform flux distribution in the receiver of a linear Fresnel solar reflector using a multi-objective genetic algorithm
}

\author{
Yu Qiu ${ }^{\mathrm{a}}$, Ming-Jia Li ${ }^{\mathrm{a} *}, \mathrm{Kun}_{\text {Wang }}^{\mathrm{a}}$, Zhan-Bin Liu ${ }^{\mathrm{a}}$, Xiao-Dai Xue ${ }^{\mathrm{b}, \mathrm{c}}$ \\ a Key Laboratory of Thermo-Fluid Science and Engineering of Ministry of Education, School of Energy and \\ Power Engineering, Xi'an Jiaotong University, Xi'an, Shaanxi, 710049, China \\ b State Key Laboratory of Control and Simulation of Power Systems and Generation Equipment, Department of \\ Electrical Engineering, Tsinghua University, Beijing 100084, China \\ c New Energy (Photovoltaic) Industry Research Center, Qinghai University, Xining 810016, China
} Corresponding author: Tel: 0086-029-82663851, E-mail: mjli1990@xjtu.edu.cn

\begin{abstract}
Non-uniform solar flux may lead to negative effects in the receiver of the linear Fresnel reflector (LFR), including the failure of the receiver and the fluctuating operation. For reducing these effects, an aiming strategy optimization approach is presented by combining a multi-objective Genetic Algorithm (GA) and Monte Carlo ray tracing to homogenize the flux distribution in current work. Both the flux non-uniformity index and the optical loss ( $\left.\eta_{\text {loss }}\right)$ are used as the objective functions. Based on the approach, first, the flux distributions in the Multi-Tube Cavity Receiver (MTCR) and the Single-Tube Receiver with a Secondary Collector (STRSC) are optimized at a typical condition. Optimal results indicate that the GA optimization strategy (S2) can reach a compromise between the flux non-uniformity and the optical loss in both MTCR and STRSC systems. Furthermore, the optimal strategy obtained at a specific transversal incidence angle can be applied in a relatively large range around it. Moreover, parameter study indicates that the aiming line number $\left(n_{\text {aim }}\right)$ has little impact on the efficiencies of the two systems. $n_{\text {aim }}$ has almost no effect on the flux non-uniformity in the MTCR, but the effect is visible in the STRSC. Finally, the application of S2 under a real-time condition indicates that fluxes in the two receivers can be homogenized efficaciously in the whole time range with a small drop of $0.2 \sim 3.8$ percentage points in efficiency compared with those of traditional one-line aiming strategy (S1). It is also found that the flux non-uniformity indexes of the MTCR are greatly reduced from $0.77 \sim 1.09$ to $0.02 \sim 0.06$ when $\mathrm{S} 1$ is replaced by S2, and those of the STRSC are steeply reduced from $0.59 \sim 0.70$ to $0.29 \sim 0.37$. It is concluded that the present approach is effective and suitable for homogenizing the fluxes in the receivers of LFRs.
\end{abstract}


Keywords: Linear Fresnel solar reflector; Aiming strategy optimization; Flux distribution non-uniformity; Optical loss; Monte Carlo ray tracing; Multi-objective genetic algorithm

\section{Introduction}

The combustion of fossil fuels has resulted in not only the tight global energy supply but also serious global environmental issues like air pollution and global warming[1-7]. For solving these problems, renewable energy technologies[8, 9], including Concentrating Solar Power (CSP)[10, 11], wind power[12], photovoltaic[13, 14], hydrogen energy[15, 16] and fuel cell technology[17-19], etc., are considered to be highly competitive candidates[20]. Among these candidates, the CSP technology is considered as a promising option[21-23] which mainly includes Linear Fresnel Reflector (LFR)[24], parabolic trough collector[25-31], solar power tower[32-37], and parabolic dish collector[38-40].

The LFR technology is a solar power technology which has attracted more attention in recent years. In an LFR, solar radiation is concentrated onto a fixed receiver by several linear mirrors, where the receiver is usually a Single-Tube Receiver with a Secondary Collector (STRSC)[41] or a Multi-Tube Cavity Receiver (MTCR)[42]. The optical performance of an LFR which determines the input power of the system is important for the system design, performance optimization and safe operation. Hence, many studies have focused on this topic nowadays.

On the one hand, some studies on LFRs using STRSCs have been carried out. Häberle et al.[43] evaluated the optical performance of the first LFR plant Solarmundo which adopts a secondary Compound Parabolic Collector (CPC). It is found that the optical efficiency of $61 \%$ is achieved at normal incidence, and the circumferential flux on the absorber tube is non-uniform. Qiu and He et al.[44] also studied the optical characteristics of an LFR using an STRSC with a CPC by a self-developed Monte Carlo ray tracing (MCRT) model. It is found that the circumferential flux can be homogenized by the CPC with $34 \%$ of the total power on the top half of the tube. Similar non-uniform fluxes have also been obtained by Balaji et al.[41] and Craig et al.[45]. Moreover, Grena and Tarquini[46] designed a new double-wing secondary collector. The simulated result shows that the circumferential flux on tube is non-uniform as well. Around $37 \%$ of the total power is on the top half.

On the other hand, some studies on LFRs using MTCRs have also been conducted. Mills and 
Morrison[47] proposed a novel design called compact linear Fresnel reflector which offers two alternative receivers to each mirror. Optical study depicts that a non-uniform flux on the receiver is observed. He et al.[48] and Moghimi et al. [49] computed the fluxes on MTCRs in LFRs adopting the MCRT method and finite volume method, respectively. Both studies found that the rays almost just shine on the lower half of the tubes, which results in the non-uniform flux on each tube. It was also found that the flux non-uniformity among the tubes is significant. Abbas et al.[50-52] and Bellos et al.[53] investigated the concentration features of flat receivers by the MCRT method and the Solidworks, respectively, where the flat receiver can be seen as the aperture of an MTCR or an STRSC. It was found that the flux on the flat receiver is significantly non-uniform with a hot region at the center.

To sum up, it can be concluded that non-uniform circumferential flux appears on each tube in both the STRSC and the MTCR. As a result, this flux will result in the non-uniform temperature on every tube, and it may lead to some negative effects. The main negative effect in the STRSC with an evacuated tube is the bending of the absorber tube[54]. This bending can be quite large, and the deflection at the middle part of the absorber tube can be $10 \mathrm{~mm}$ after the receiver is used for one year in a trough system[55]. This large deformation can lead to the vacuum failure and the glass envelop fracture[56, 57]. Data from the SEGS plant indicate that $3.37 \%$ of the total field receivers failed per year. In the MTCR, ordinary tubes without glass envelop are employed. The tubes can cope with non-uniform temperatures, because it is no need to worry about the glass breakage. As a result, the uniformity of the circumferential flux is not as important for MTCR as it is with STRSC. It is also found that the flux among tubes in the MTCR is quite non-uniform, which may result in the unstable operation due to the uneven heating of the fluid among the tubes when parallel flow is employed. Moreover, it should also be noted that the local high temperature can accelerate the degradation of coating when there is no vaccum and cause the decomposition of the heat transfer fluid $[43,58,59]$.

To overcome these negative effects, it is necessary to improve the flux uniformity in the receiver. Review of above mentioned literatures indicates that few studies have focused on this topic.

To provide better studies for solving these problems, this work focuses on developing an optimization approach to reducing the flux non-uniformity in LFRs. The main contributions are 
summarized as:

(1) The originality of this work is that a multi-objective optimization approach combining Monte Carlo ray tracing (MCRT) and the genetic algorithm (GA) was developed for homogenizing the flux distributions in LFRs. LFRs with two typical receivers were studied to illustrate the application of the approach in practice, including a multi-tube cavity receiver and a single-tube receiver with a secondary collector.

(2) Optimization results with different typical conditions indicate that flux distributions in two typical receivers can be homogenized efficaciously in the whole range of the incident angle with a small drop of efficiency.

\section{Physical model and aiming strategies}

\subsection{Physical model}

The LFR primary mirror field with 25 cylindrical mirrors is taken as the concentrator[44, 48]. A Multi-Tube Cavity Receiver (MTCR)[48] and a Single-Tube Receiver with a Secondary Collector (STRSC)[44] are considered as the receiver module, respectively. The configuration of the LFR is illustrated in Fig. 1 and Fig. 2. The geometric and optical parameters are shown in Table 1. Several Cartesian coordinate systems are established in Fig. 1 and Fig. 2 for describing the model. $X_{\mathrm{g}} Y_{\mathrm{g}} Z_{\mathrm{g}}$ is the ground system, where the southern end of the field's middle line is the origin $(\boldsymbol{G})$, and $X_{\mathrm{g}}, Y_{\mathrm{g}}$, and $Z_{\mathrm{g}}$ point to the south, east, and zenith, respectively. $X_{\mathrm{m}} Y_{\mathrm{m}} Z_{\mathrm{m}}$ is the mirror system, where the southern end of each mirror's middle line is the origin $(M) . X_{\mathrm{m}}$ points towards the south, and $Z_{\mathrm{m}}$ is normal to the mirror's tangent plane at $M$ and points to the upside of the mirror. $Y_{\mathrm{m}}$ is normal to $X_{\mathrm{m}} Z_{\mathrm{m}}$ plane. $X_{\mathrm{r}} Y_{\mathrm{r}} Z_{\mathrm{r}}$ is the receiver system. The intersection of $Z_{\mathrm{g}}$ axis and the plane $z_{\mathrm{g}}=H_{\mathrm{t}}$ in $X_{\mathrm{g}} Y_{\mathrm{g}} Z_{\mathrm{g}}$ is the origin $(O)$, where $H_{\mathrm{t}}$ is the height of the axes of the tubes in $X_{\mathrm{g}} Y_{\mathrm{g}} Z_{\mathrm{g}} . X_{\mathrm{r}}, Y_{\mathrm{r}}, Z_{\mathrm{r}}$ point to the south, east, and zenith, respectively.

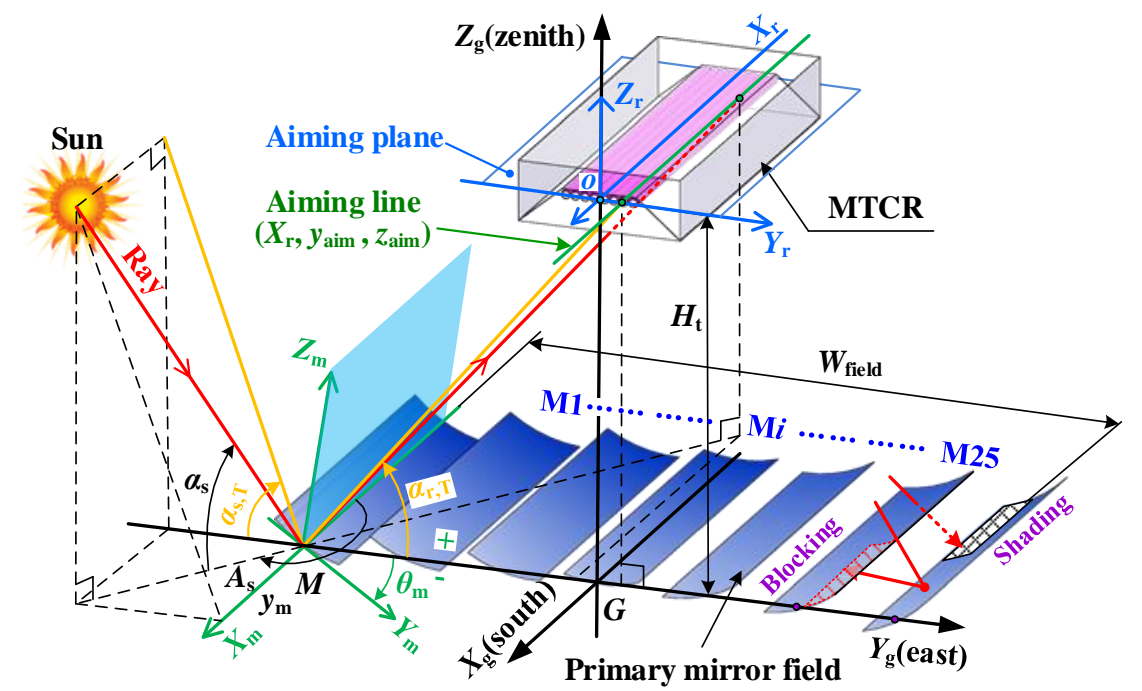

Fig. 1. Sketch of an LFR showing the transfer of the solar ray. 


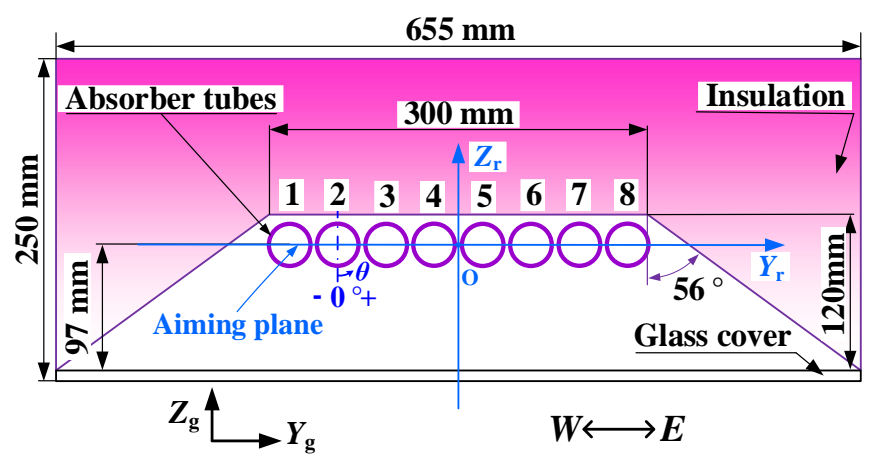

(a) MTCR

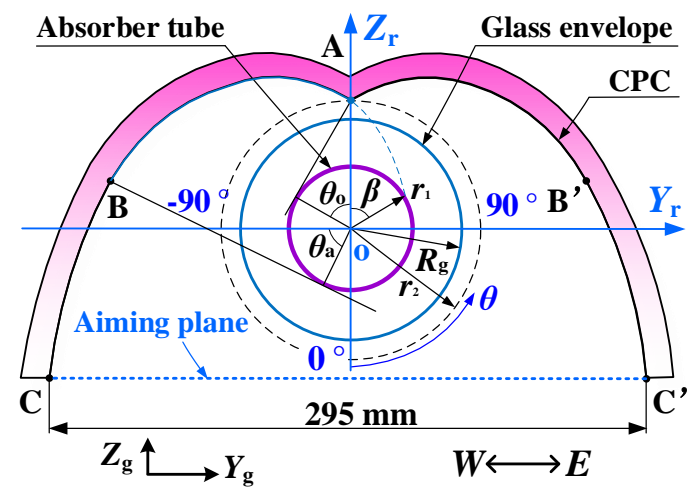

(b) STRSC

Fig. 2. Sketches of Multi-tube Cavity Receiver(MTCR) and Single-Tube Receiver with a Secondary Collector(STRSC).

Table 1 Geometric and optical parameters of the LFR $[42,43,60,61]$.

\begin{tabular}{llll}
\hline Parameters & Value & Parameters & Value \\
\hline Primary mirror number $n_{\mathrm{m}}$ & 25 & Diffuse reflectance of MTCR's wall & 0.77 \\
Width of the field $W_{\text {field }}$ & $20.4 \mathrm{~m}$ & Coating absorptivity in MTCR & 0.93 \\
Width of the mirror $W_{\mathrm{m}}$ & $0.6 \mathrm{~m}$ & Coating diffuse reflectance in MTCR & 0.07 \\
Length of collector $L_{\mathrm{m}}$ & $100 \mathrm{~m}$ & Aperture width of CPC & $295 \mathrm{~mm}$ \\
Distance between two mirrors & $0.85 \mathrm{~m}$ & Thickness of CPC & $5 \mathrm{~mm}$ \\
Specular reflectance of mirror & 0.92 & Half acceptance angle of CPC $\theta_{\mathrm{a}}$ & $56^{\circ}$ \\
slope error of mirror and CPC & $1.0 \mathrm{mrad}$ & $\theta_{\text {omax }}$ & $3.37 \mathrm{rad}$ \\
Height of the tube in LFR $H_{\mathrm{t}}$ & $8.0 \mathrm{~m}$ & $r_{2}$ & $62.5 \mathrm{~mm}$ \\
Cavity's bottom width of MTCR & $655 \mathrm{~mm}$ & Tube's outer radius in STRSC $r_{1}$ & $35 \mathrm{~mm}$ \\
Cavity's top width o of MTCR & $300 \mathrm{~mm}$ & Envelope's outer radius $R_{\mathrm{g}}$ & $57.5 \mathrm{~mm}$ \\
Half acceptance angle of MTCR & $56^{\circ}$ & Thickness of envelope & $3 \mathrm{~mm}$ \\
Depth of MTCR & $120 \mathrm{~mm}$ & Absorptivity/specular reflectance of CPC & $0.05 / 0.95$ \\
Number of tubes in MTCR $n_{\mathrm{t}}$ & 8 & Glass transmittance/absorptivity & $0.96 / 0.02$ \\
Tube outer diameter in MTCR & $36 \mathrm{~mm}$ & Glass specular reflectance & 0.02 \\
Gap between two tubes in MTCR & $3 \mathrm{~mm}$ & Glass refraction index & 1.47 \\
Glass cover thickness in MTCR & $3 \mathrm{~mm}$ & Coating absorptivity in STRSC & 0.96 \\
Absorptivity of MTCR's wall & 0.15 & Coating diffuse reflectance in STRSC & 0.04 \\
Specular reflectance of MTCR's wall & 0.08 & Angular radius of sun rays & $4.65 \mathrm{mrad}$ \\
\hline
\end{tabular}

The mirror field is symmetrical about its middle line. Two mirrors at symmetric positions have the same the dimensions. The mirrors are numbered M1 to M25 from the west to the east as shown in Fig. 1 and Fig. 3. The mirrors with non-constant curvatures were designed for concentrating as much power as possible, and the curvature radiuses $R_{\mathrm{m}}$ for M13 M25 are given in Eq.(1)[48]. The MTCR which includes eight absorber tubes is covered by a glass plate at the bottom. It is covered by aluminum walls and asbestos on the top as shown in Fig. 2(a). The STRSC includes a CPC and an 
evacuated tube as shown in Fig. 2(b). The equations of the CPC profiles $\mathrm{AB}$ and $\mathrm{BC}$ in $X_{\mathrm{r}} Y_{\mathrm{r}} Z_{\mathrm{r}}$ are expressed in Eqs.(2) and (3)[62].

$$
\begin{gathered}
R_{\mathrm{m}}(i)=\left\{\begin{array}{c}
16.1+(i-13)[0.10+0.10(i-14)], 13 \leq i \leq 19 \\
14.3+(i-13)[0.65+0.05(i-14)], 20 \leq i \leq 25
\end{array}\right. \\
\qquad\left\{\begin{array}{l}
y_{\mathrm{r}}=\rho_{\mathrm{o}} \cos \theta_{\mathrm{o}}-r_{1} \sin \theta_{\mathrm{o}} \\
z_{\mathrm{r}}=\rho_{\mathrm{o}} \sin \theta_{\mathrm{o}}+r_{1} \cos \theta_{\mathrm{o}}
\end{array}\right. \\
\mathrm{AB}: \rho_{\mathrm{o}}=r_{1}\left(\theta_{\mathrm{o}}+\beta\right), \arccos \left(\frac{r_{1}}{r_{2}}\right) \leq \theta_{\mathrm{o}} \leq \frac{\pi}{2}+\theta_{\mathrm{a}}
\end{gathered}
$$

where $i$ is the ordinal number of the mirrors; other geometric parameters are given in Table 1.

\subsection{One-line strategy and GA optimization strategy}

The aiming line $\left(X_{\mathrm{r}}, y_{\mathrm{aim}}, z_{\mathrm{aim}}\right)$ in $X_{\mathrm{r}} Y_{\mathrm{r}} Z_{\mathrm{r}}$ for a mirror is a line which is on the aiming plane of $z_{\mathrm{r}}=$ $z_{\text {aim }}$ in $X_{\mathrm{r}} Y_{\mathrm{r}} Z_{\mathrm{r}}$ and hit by the rays reflected on the center line of the mirror as shown in Fig. 1 and Fig. 3, where $y_{\text {aim }}$ and $z_{\text {aim }}$ are the $y$ value and $z$ value of the aiming line in $X_{\mathrm{r}} Y_{\mathrm{r}} Z_{\mathrm{r}}$. The aiming plane in the MTCR is at the axes of the tubes, where $z_{\mathrm{aim}}=0$. The aiming plane in the STRSC is at the aperture of the CPC, where $z$ aim $=-70 \mathrm{~mm}$.

A basic aiming strategy for LFRs is the one-line aiming strategy (S1) as illustrated in Fig. 3(a), where all mirrors aim at the center line of the aiming plane. In current work, a new optimization strategy (S2) is presented and illustrated in Fig. 3(b) for distributing the flux in the receiver

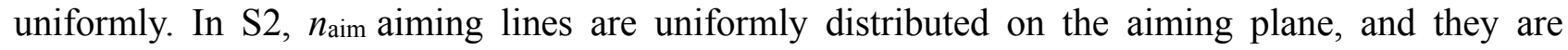
numbered $\mathrm{A} 1$ to $\mathrm{A} n_{\text {aim }}$ from the west to the east. Each mirror would choose an aiming line from the

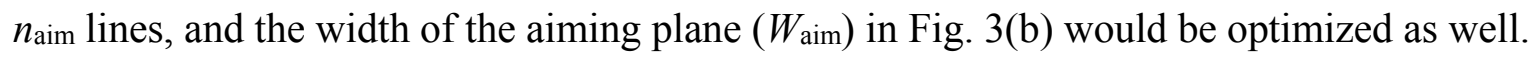




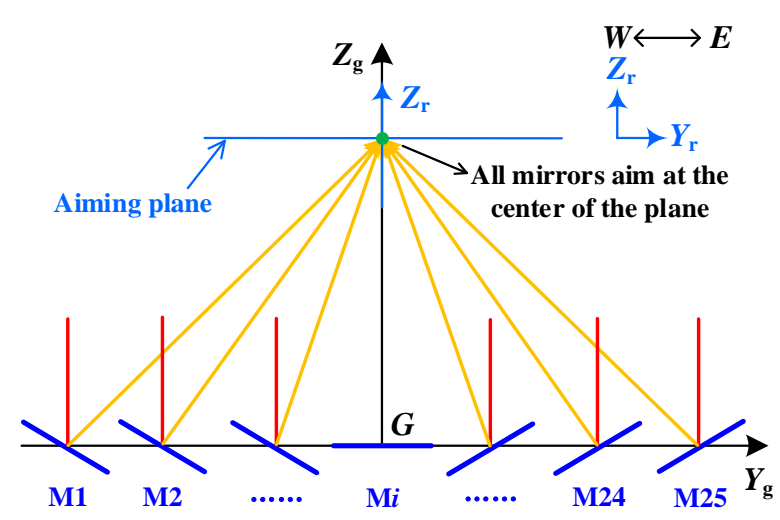

(2) One-line aiming strategy (S1)

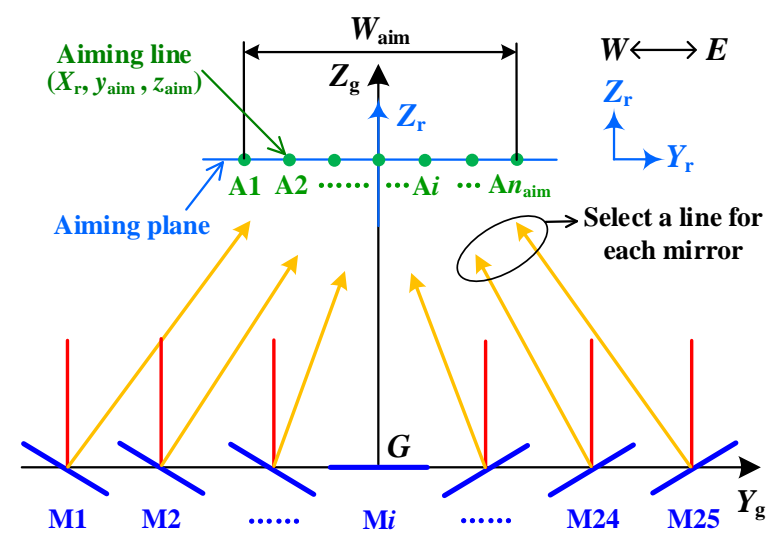

(b) GA optimization strategy (S2)

Fig. 3. Sketches of two aiming strategies for LFRs.

\section{Mathematical model}

The aiming strategy was optimized by combining an MCRT model and a multi-objective GA. The flowchart of the optimization is shown in Fig. 4. In the optimization, the MCRT model is used to predict the flux distribution in the receiver and calculate the optical efficiency. The GA is adopted to optimize the flux distribution.

Due to the structural characteristics of the LFR, it is known that the longitudinal components of the incident solar rays have no effect on the flux non-uniformity in the receiver. Therefore, only the aiming strategies at different values of the transversal incidence angle $\left(\alpha_{\mathrm{s}, \mathrm{T}}\right)$, which is the angle between the projection of an incident ray on $Y_{\mathrm{g}} Z_{\mathrm{g}}$ plane and $Y_{\mathrm{g}}$ as shown in Fig. 1, are needed to be optimized. In current optimization, the sun rays are assumed from the east when the solar azimuth $\left(A_{\mathrm{s}}\right)$ is $90^{\circ}$, and $\alpha_{\mathrm{s}, \mathrm{T}}$ is equal to the solar altitude $\left(\alpha_{\mathrm{s}}\right)$.

For each receiver, two objective functions are optimized, including a non-uniformity index of the flux distribution and the optical loss $\left(\eta_{\text {loss }}\right)$. The non-uniformity index $\left(f_{\mathrm{ST}}\right)$ of the STRSC is defined as the relative standard deviation of values of the flux in the circumferential elements on the absorber tube as given in Eq.(4). The non-uniformity index $\left(f_{\mathrm{MT}}\right)$ for the MTCR is defined as the relative standard deviation of values of power absorbed on all tubes as given in Eq.(5). $\eta$ loss is defined in Eq.(6). The optical efficiency $\left(\eta_{\mathrm{opt}}\right)$ is the ratio of the power absorbed by the tube and the maximum power that can be accepted by the mirrors.

$$
f_{\mathrm{ST}}=\frac{\sqrt{\sum_{i=1}^{n_{\mathrm{e}}}\left[q_{1}(i)-\bar{q}_{1}\right]^{2} /\left(n_{\mathrm{e}}-1\right)}}{\bar{q}_{1}}, \bar{q}_{1}=\frac{\sum_{i=1}^{n_{\mathrm{e}}} q_{1}(i)}{n_{\mathrm{e}}}
$$




$$
\begin{gathered}
f_{\mathrm{MT}}=\frac{\sqrt{\sum_{i=1}^{n_{\mathrm{t}}}\left[E_{\mathrm{t}}(i)-\bar{E}_{\mathrm{t}}\right]^{2} /\left(n_{\mathrm{t}}-1\right)}}{\bar{E}_{\mathrm{t}}}, \bar{E}_{\mathrm{t}}=\frac{\sum_{i=1}^{n_{\mathrm{t}}} E_{\mathrm{t}}(i)}{n_{\mathrm{t}}} \\
\eta_{\text {loss }}=1-\eta_{\text {opt }}, \eta_{\text {opt }}=\frac{Q}{D N I \cdot L_{\mathrm{m}} W_{\mathrm{m}} n_{\mathrm{m}}} \times 100 \%
\end{gathered}
$$

where $n_{\mathrm{e}}$ is the number of the circumferential elements on the tube in STRSC; $n_{\mathrm{t}}$ is the number of the tubes; $q_{1}(i)$ is local flux in $i$ th element; $E_{\mathrm{t}}(i)$ is the power absorbed by $i$ th tube; $Q$ and $D N I$ are the power absorbed by the tube and the direct normal irradiance of the sun, respectively.

The detailed model is introduced in the following sections.

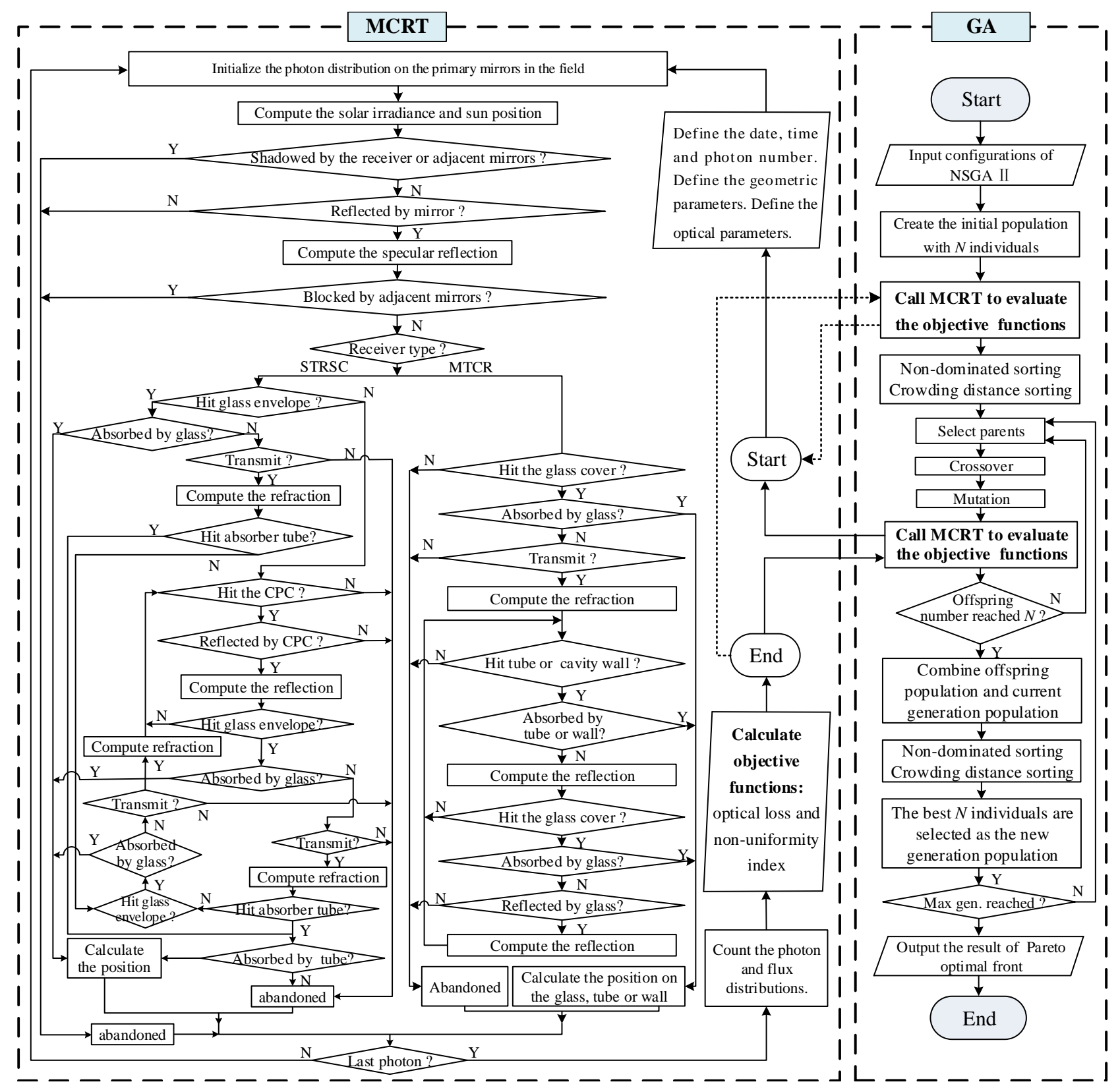

Fig. 4. Flowchart for the code of the GA optimization approach.

\subsection{Optical model based on Monte Carlo ray tracing}

The solar ray transfer from the sun to the receiver is simulated by a three-dimensional optical 
model developed based on the Monte Carlo ray tracing (MCRT), which is an optical simulation method that has been widely used in CSPs [63-65]. The code was programmed in FORTRAN, and the flowchart is illustrated on the left side in Fig. 4. The details of the model which can be found in Refs.[44] and [48] are omitted here, and some important information is introduced as follows.

The tracking angle of a mirror $\left(\theta_{\mathrm{m}}\right)$ is defined as the angle between the positive directions of $Y_{\mathrm{m}}$ and $Y_{\mathrm{g}}$. In the northern hemisphere, the tracking angle $\theta_{\mathrm{m}}$ for a western mirror is given in Eq.(7). $\theta_{\mathrm{m}}$ at other conditions can be obtained in the similar way[44].

$$
\begin{gathered}
\theta_{\mathrm{m}}=0.5 \cdot\left(\alpha_{\mathrm{r}, \mathrm{T}}-\alpha_{\mathrm{s}, \mathrm{T}}\right) \\
\alpha_{\mathrm{s}, \mathrm{T}}=\tan ^{-1}\left(\frac{\tan \alpha_{\mathrm{s}}}{\sin \left|A_{\mathrm{s}}-\pi\right|}\right), \alpha_{\mathrm{r}, \mathrm{T}}=\tan ^{-1}\left|\frac{H_{\mathrm{t}}}{y_{\mathrm{aim}}-y_{\mathrm{m}}}\right|
\end{gathered}
$$

where $y_{\mathrm{m}}$ is the $y$ value of the mirror's center line in $X_{\mathrm{g}} Y_{\mathrm{g}} Z_{\mathrm{g}} ; \alpha_{\mathrm{s}}$ and $A_{\mathrm{s}}$ are the solar altitude and azimuth, which can be obtained when the local latitude $\varphi$, real solar time $t_{\mathrm{s}}$ and the ordinal of a day in a year are provided[48]; $\alpha_{\mathrm{s}, \mathrm{T}}$ is the transversal incidence angle which is the angle between the projection of an incident ray on $Y_{\mathrm{g}} Z_{\mathrm{g}}$ plane and $Y_{\mathrm{g}}$ as shown in Fig. 1; $\alpha_{\mathrm{r}, \mathrm{T}}$ is the angle between the projection of the reflected ray on $Y_{\mathrm{g}} Z_{\mathrm{g}}$ plane and $Y_{\mathrm{g}}$.

The solar rays are initialized randomly and uniformly on the mirrors. The sun shape error is considered as a pillbox with an angular radius of $4.65 \operatorname{mrad}[44]$. The real-time DNI of the annual solar radiation is calculated by a clear sky radiation model[66], and the power of each ray $(e)$ is calculated by Eq.(9).

$$
e=D N I \cdot L_{\mathrm{m}} W_{\mathrm{m}} \sum_{i=1}^{n_{\mathrm{m}}} \eta_{\text {cos }}(i) / n_{\mathrm{ray}}
$$

where $\eta_{\cos }(i)$ is the cosine efficiency of the $i$ th mirror; $n_{\text {ray }}$ is the total number of the traced rays.

Quadrilateral meshes are generated on all surfaces in the MTCR and the STRSC to count the rays absorbed on these surfaces. The sketches of the meshes are illustrated in Fig. 5. In all computations processes, the mesh systems with 60 and 68 circumferential elements on each absorber tube are used in the MTCR and the STRSC, respectively. In the optimization process, only one lengthwise element for each tube in the two receivers is adopted to reduce the amount of calculation. In the flux computation process, 200 lengthwise elements for each tube in the two receivers are used for revealing the detailed fluxes.

If a ray is absorbed, it will be counted in the number of the rays absorbed in the local element 
( $\left.n_{\text {ray,e }}\right)$ where the ray is absorbed. The local flux in each element $\left(q_{1}\right)$ will be calculated after the tracing of the last ray by Eq.(10). The Local Concentration Ratio $(L C R)$ is defined as the ratio of the local solar flux $(q 1)$ and $D N I$ as shown in Eq.(11).

$$
\begin{aligned}
& q_{1}=e \cdot n_{\text {ray, }} / S_{\mathrm{e}} \\
& L C R=q_{1} / D N I
\end{aligned}
$$

where $S_{\mathrm{e}}$ is the area of the local element.

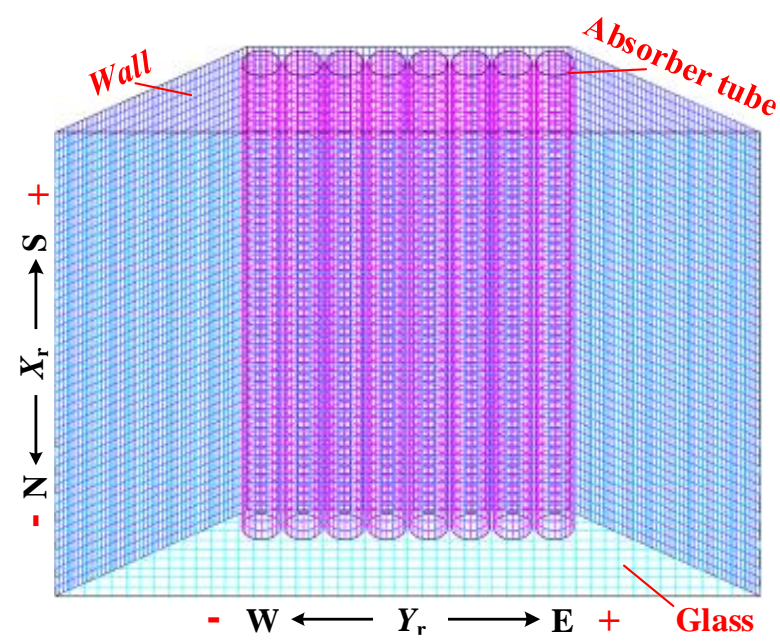

(a) MTCR



(b) STRSC

Fig. 5. Sketches of the meshes in MTCR and STRSC.

\subsection{Optimization model based on a multi-objective GA}

Genetic algorithm (GA) primarily presented by Prof. John Henry Holland in 1975 is a kind of evolutionary algorithm which imitates the processes of biology evolution in nature[67], and it is viewed as an effective method for optimization problems[68-71]. In current model, a revised version called Non-dominated Sorting Genetic Algorithm II (NSGA-II)[72] for the multi-objective optimization is adopted to solve the present problem.

At the beginning of the optimization, a population with $N$ individuals is randomly initialized, and each individual $(g)$ is stored in a vector of $\left(n_{\mathrm{m}}+1\right)$ genes $\left(g_{i}\right)$ as expressed in Eq.(12). The first $n_{\mathrm{m}}$ genes in an individual are integer numbers, and each $g_{i}$ is the ordinal number of the aiming line for corresponding $i$ th mirror $(\mathrm{M} i)$. The last gene $g_{n_{\mathrm{m}}+1}$ is a real number which represents the width of the aiming plane $\left(W_{\text {aim }}\right)$. In current optimization, $N=50$ is used, and the lower bound $\left(g_{i}^{\mathrm{L}}\right)$ and upper bound $\left(g_{i}^{\mathrm{U}}\right)$ for $g_{i}$ are given in Eq.(13).

$$
g=\left(g_{1}, g_{2}, \cdots, g_{n_{\mathrm{m}}}, g_{n_{\mathrm{m}}+1}\right)
$$




$$
\left\{\begin{array}{l}
g_{i}^{\mathrm{L}}=1, \quad g_{i}^{\mathrm{U}}=n_{\mathrm{aim}}, \quad 1 \leq i \leq n_{\mathrm{m}} \\
g_{i}^{\mathrm{L}}=50 \mathrm{~mm}, g_{i}^{\mathrm{U}}=300 \mathrm{~mm}, \quad i=n_{\mathrm{m}}+1
\end{array}\right.
$$

After that, the procedures including non-dominated sorting, crowding distance sorting, and tournament selection, crossover, mutation, recombination and selection are applied to produce the new population from the old one. This process will be repeated for plenty of generations. In current optimization, the maximum generation number of 500 is used. At the end of the optimization, a Pareto optimal front which provides $N$ optimal individuals can be obtained.

\subsection{Solution selection from the Pareto front}

The Pareto front shows a trade-off between the flux distribution non-uniformity and the optical loss. In practice, a compromise has to be found between the non-uniformity and the optical loss. Therefore, a method called Technique for Order Preference by Similarity to an Ideal Solution (TOPSIS)[73] and a limitation called efficiency limitation are used to select the optimal solution from the Pareto front.

The procedure of TOPSIS is as follows. First, the non-uniformity index ( $f_{\mathrm{ST}}$ or $\left.f_{\mathrm{MT}}\right)$ and the optical loss $\left(\eta_{\text {loss }}\right)$ for each optimal individual are normalized using Eq.(14). Then, two distances $\left(d_{i}^{+}, d_{i}^{-}\right)$are calculated by Eq.(15). Finally, the individual which holds the greatest value of $r_{i}^{*}$ in Eq.(16) will be selected as the suggested solution.

$$
\begin{gathered}
\left\{\begin{array}{l}
f_{i}^{*}=f_{i} / \sqrt{\sum_{i=1}^{N} f_{i}^{2}} \\
\eta_{\mathrm{loss}, i}^{*}=\eta_{\mathrm{loss}, i} / \sqrt{\sum_{i=1}^{N} \eta_{\mathrm{loss}, i}^{2}}
\end{array}\right. \\
\left\{\begin{array}{l}
d_{i}^{-}=\sqrt{\left[\eta_{\mathrm{loss}, i}^{*}-\max \left(\eta_{\mathrm{loss}, i}^{*}\right)\right]^{2}+\left[f_{i}^{*}-\max \left(f_{i}^{*}\right)\right]^{2}} \\
d_{i}^{+}=\sqrt{\left[\eta_{\mathrm{loss}, i}^{*}-\min \left(\eta_{\mathrm{loss}, i}^{*}\right)\right]^{2}+\left[f_{i}^{*}-\min \left(f_{i}^{*}\right)\right]^{2}} \\
r_{i}^{*}=d_{i}^{-} /\left(d_{i}^{+}+d_{i}^{-}\right)
\end{array}\right.
\end{gathered}
$$

Where $i=1,2, \ldots, N ; f$ represents $f_{\mathrm{ST}}$ or $f_{\mathrm{MT}} ; \min \left(x_{i}\right)$ and $\max \left(x_{i}\right)$ represent the minimum and maximum values of $x_{i}$, respectively.

For avoiding significant decrease in optical efficiency, an efficiency limitation is also used to choose the solution in the following way. First, a group of optimal individuals, which meet the limitation in Eq.(17), is selected from the Pareto front. $\lambda$ in Eq.(17) is a coefficient that is adopted to 
limit the optical loss. $\lambda$ of 0.95 is used in current optimization. It should be noted that the value of $\lambda$ can be adjusted based on the requirement of the optimization. Second, the individual which has the minimum efficiency in the group is selected as the suggested solution.

$$
\eta_{\mathrm{opt}}(\mathrm{S} 2) \geq \lambda \cdot \eta_{\mathrm{opt}}(\mathrm{S} 1)
$$

where $\eta_{\mathrm{opt}}(\mathrm{S} 2)$ and $\eta_{\mathrm{opt}}(\mathrm{S} 1)$ are the efficiencies when $\mathrm{S} 2$ and $\mathrm{S} 1$ are used, respectively.

After the above two procedures, the efficiency of the solution suggested by the TOPSIS is compared with the suggested solution of the efficiency limitation. If the former is larger than the latter, the solution suggested by the TOPSIS will be chosen as the final optimal solution. Otherwise, the suggested solution of the efficiency limitation will be selected.

\section{Model validation}

The MCRT model is validated as follows. First, the $L C R$ profile on the focal plane of an LFR with 30 mirrors is calculated under normal incidence and compared with the experimental results provided by Chemisana et al.[74] as shown in Fig. 6, where the mirror slope error is $12.5 \mathrm{mrad}$. It is seen that two curves correspond with each other, and the relative deviations are less than $1.6 \%$. Furthermore, the $L C R$ profiles on the tubes of the MTCR in current LFR are computed at a typical condition with the solar altitude $\left(\alpha_{\mathrm{s}}\right)$ of $45^{\circ}$ and the solar azimuth $\left(A_{\mathrm{s}}\right)$ of $135^{\circ}$. The $\mathrm{S} 1$ is used, and the diffuse reflection in the MTCR is treated as the specular reflection in this case, which is the same as that of SolTrace. The results are compared with those computed by the SolTrace[75] in Fig. 7. It can be found that the $L C R$ profiles of the present model agree with those of SolTrace well on both tube 3 and tube 4 in Fig. 2(a), respectively. These good agreements indicate that the current model is reliable.

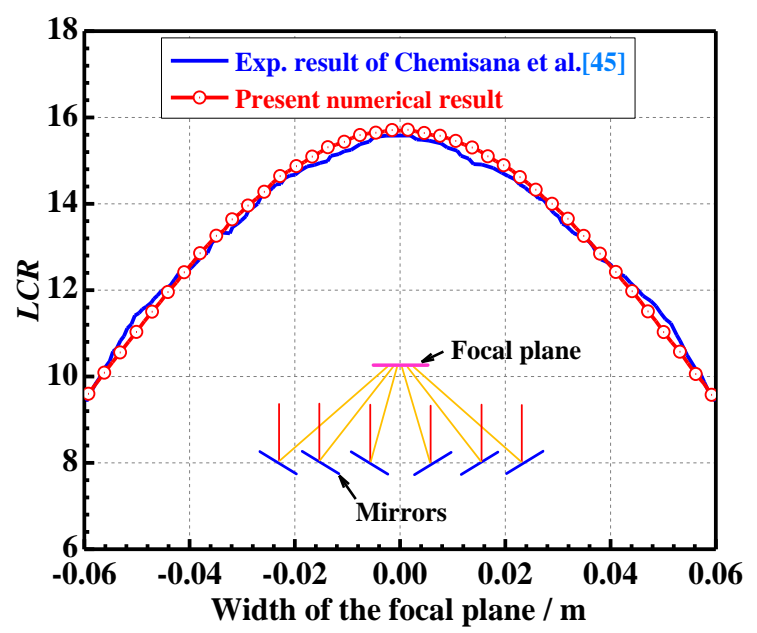

Fig. 6. Comparison of present result and experimental result in Ref.[74].

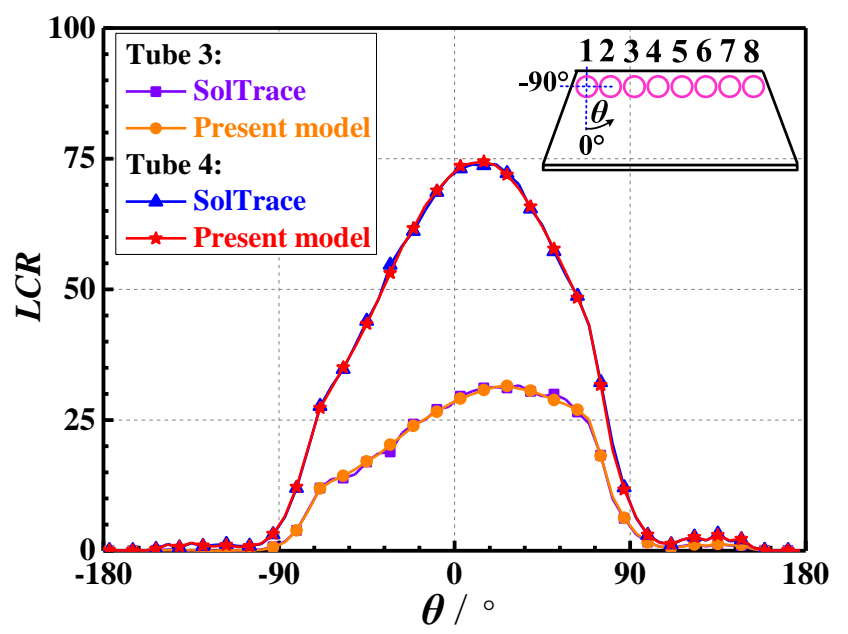

Fig. 7. Comparison of the results between present model and SolTrace[75].

\section{Results and discussion}




\subsection{Optimal results under a typical condition}

Optimal flux distributions under a typical condition of $\alpha_{\mathrm{s}, \mathrm{T}}=\alpha_{\mathrm{s}}=45^{\circ}$ and $A_{\mathrm{s}}=90^{\circ}$ are taken as examples to illustrate the typical optimization results. In the optimization, the aiming line number ( $n_{\text {aim}}$ ) of 11 is considered in both MTCR and STRCSC systems. The values of the computation time are 48 minutes and 38 minutes for the two systems, respectively. The computer used has $8 \mathrm{~GB}$ of RAM and eight Intel(R) Core(TM) i7-6700 CPUs which have the clock speed of $3.40 \mathrm{GHz}$ for each.

\subsubsection{Optimal solutions and flux distributions}

Fig. 8 shows the Pareto fronts of the optimizations for the two systems. It can be seen that the optical loss ( $\eta$ loss $)$ decreases with the ascending non-uniformity index for each system. The solutions selected by the TOPSIS and the efficiency limitation are also marked, and the solutions obtained by the efficiency limitation are selected for the two cases adopting the selection approach introduced in Section 3.3. Details of the optimal solutions are given in Table 2.

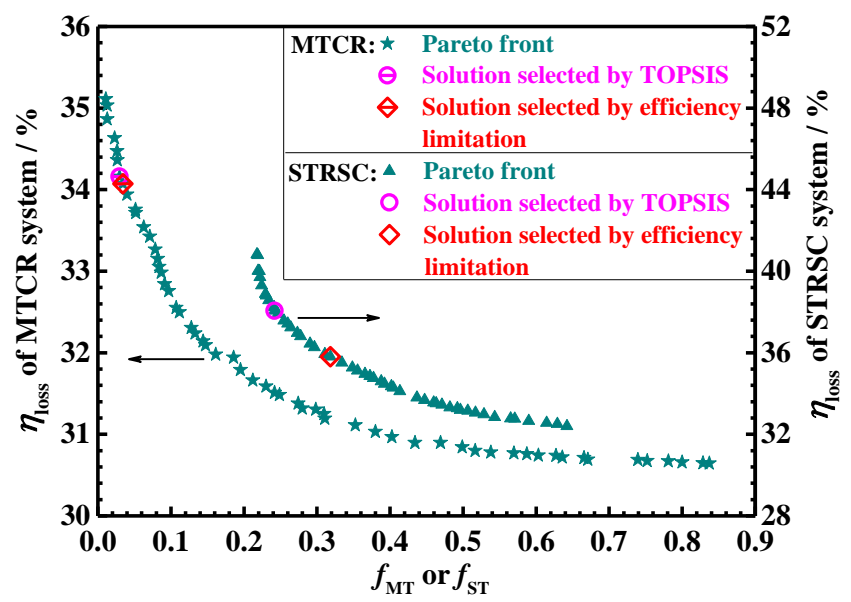

Fig. 8. Pareto fronts of MTCR and STRCSC systems when $\alpha_{\mathrm{s}, \mathrm{T}}=\alpha_{\mathrm{s}}=45^{\circ}$ and $A_{\mathrm{s}}=90^{\circ}$.

Table 2. Optimal solutions for MTCR and STRCSC systems when $\alpha_{\mathrm{s}, \mathrm{T}}=\alpha_{\mathrm{s}}=45^{\circ}$ and $A_{\mathrm{s}}=90^{\circ}$.

\begin{tabular}{|c|c|c|c|c|c|c|c|c|c|c|c|c|c|c|}
\hline \multirow{4}{*}{$\begin{array}{l}\text { MTCR, } \\
n_{\text {aim }}=11\end{array}$} & $i$ & 1 & 2 & 3 & 4 & 5 & 6 & 7 & 8 & 9 & 10 & 11 & 12 & 13 \\
\hline & $g_{i}$ & 7 & 10 & 2 & 5 & 1 & 6 & 11 & 2 & 7 & 11 & 1 & 1 & 4 \\
\hline & $i$ & 14 & 15 & 16 & 17 & 18 & 19 & 20 & 21 & 22 & 23 & 24 & 25 & 26 \\
\hline & $g_{i}$ & 10 & 3 & 9 & 6 & 4 & 5 & 9 & 9 & 10 & 5 & 7 & 7 & $255 \mathrm{~mm}$ \\
\hline \multirow{4}{*}{$\begin{array}{c}\text { STRSC, } \\
n_{\text {aim }}=11\end{array}$} & $i$ & 1 & 2 & 3 & 4 & 5 & 6 & 7 & 8 & 9 & 10 & 11 & 12 & 13 \\
\hline & $g_{i}$ & 4 & 3 & 6 & 1 & 7 & 4 & 1 & 8 & 9 & 1 & 7 & 11 & 2 \\
\hline & $i$ & 14 & 15 & 16 & 17 & 18 & 19 & 20 & 21 & 22 & 23 & 24 & 25 & 26 \\
\hline & $g_{i}$ & 3 & 4 & 11 & 9 & 6 & 9 & 10 & 9 & 6 & 4 & 4 & 4 & $145 \mathrm{~mm}$ \\
\hline
\end{tabular}

Fig. 9 illustrates the $L C R$ distributions in the MTCR for the one-line strategy (S1) and GA optimization strategy (S2). It can be found in Fig. 9(a) that the flux distribution non-uniformity is 
significant for $\mathrm{S} 1$ with $f_{\mathrm{MT}}=1.01$, where most rays shine on tube 4 and tube 5, while tube 1 and tube 8 are barely utilized. As a result, the $L C R_{\max }$ of 88.5 appears on tube 5. However, it is seen in Fig. 9(b) that the flux of $\mathrm{S} 2$ is quite uniform with $f_{\mathrm{MT}}=0.03$ and $L C R \max$ of 34.5 on tube 2 . It is also presented that the drops in $f_{\mathrm{MT}}$ and $L C R_{\max }$ are $97 \%$ and $61 \%$ compared with those of $\mathrm{S} 1$, respectively. In addition, it is found that the optical efficiency $\left(\eta_{\mathrm{opt}}\right)$ of $\mathrm{S} 2$ is 3.3 percentage points lower than that of S1.

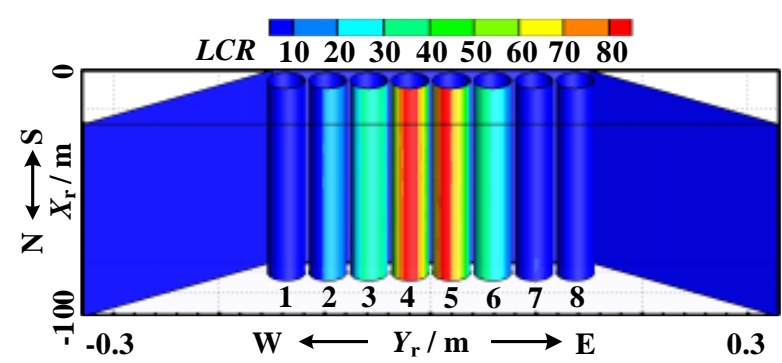

(a) S1: $f_{\mathrm{MT}}=1.01, L C R_{\max }=88.5, \eta_{\mathrm{opt}}=69.3 \%$.

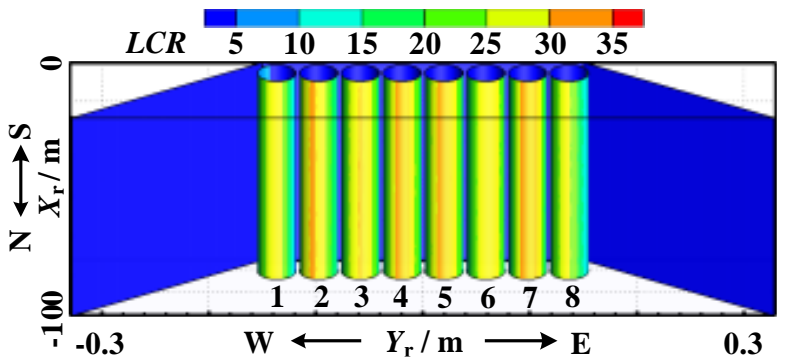

(b) S2 with $n_{\text {aim }}=11: W_{\text {aim }}=255 \mathrm{~mm}, f_{\mathrm{MT}}=0.03$,

$$
L C R_{\max }=34.5, \eta_{\mathrm{opt}}=66.0 \%
$$

Fig. 9. Comparison of flux distributions in MTCR between two aiming strategies when $\alpha_{\mathrm{s}, \mathrm{T}}=\alpha_{\mathrm{s}}=45^{\circ}$ and $A_{\mathrm{s}}=90^{\circ}$.

Fig. 10 shows the $L C R$ distributions on the absorber tube in the STRSC for the two aiming strategies $(\mathrm{S} 1, \mathrm{~S} 2)$. It is presented that the flux is significantly non-uniform for $\mathrm{S} 1$ with $f_{\mathrm{ST}}=0.67$ and $L C R_{\max }=95.4$, where only $22 \%$ of the total power is on the top half of the tube. However, it is seen that the flux of $\mathrm{S} 2$ is quite uniform with $f_{\mathrm{ST}}=0.32$ and $L C R_{\max }=62.1$, where $f_{\mathrm{ST}}$ and $L C R_{\max }$ are reduced by $52 \%$ and $35 \%$ compared with those of S1, respectively. It is worth noting that $38 \%$ of the total power shines on the top half of the absorber of S2, which could help to reduce the bending of the tube and protect the glass envelope from vacuum failure. Moreover, it can be found that the drop in efficiency of $\mathrm{S} 2$ is 3.3 percentage points compared with that of $\mathrm{S} 1$. This is because more rays are lost through the gap between the top of the absorber and the CPC when S2 is used.



Fig. 10. Comparison of flux profiles in STRSC between two aiming strategies when $\alpha_{\mathrm{s}, \mathrm{T}}=\alpha_{\mathrm{s}}=45^{\circ}$ and $A_{\mathrm{s}}=90^{\circ}$. 
The above results indicate that the optimization strategy can reach a reasonable compromise between the flux distribution non-uniformity and the optical loss under the typical $\alpha_{\mathrm{s}, \mathrm{T}}$.

\subsubsection{Influence of the number of aiming lines}

In the optimization, the number of the aiming lines $\left(n_{\text {aim }}\right)$ is the only parameter of the aiming strategy which is not optimized. So, its effect is further discussed in this section under the above typical condition.

Fig. 9(b) and Fig. 11 show the optimal flux distributions in the MTCR at different aiming line numbers $\left(n_{\text {aim }}\right)$. It can be found that the optimal result of $W_{\text {aim }}$ varies with the variation of $n_{\text {aim. }}$. It is also seen that the differences among the flux distributions for all cases with $n_{\text {aim }}=5 \sim 19$ are not obvious, where $f_{\mathrm{MT}}$ and $L C R_{\max }$ are in the ranges of $0.07 \sim 0.03$ and 34.2 36.3, respectively. Moreover, it is found that $\eta_{\mathrm{opt}}$ is in the range of $66.0 \% \sim 66.2 \%$ for all cases. These results indicate that $n$ aim has little impact on neither flux non-uniformity nor optical efficiency of the MTCR system. In the following discussion, $n_{\mathrm{aim}}=11$ is used for the MTCR.

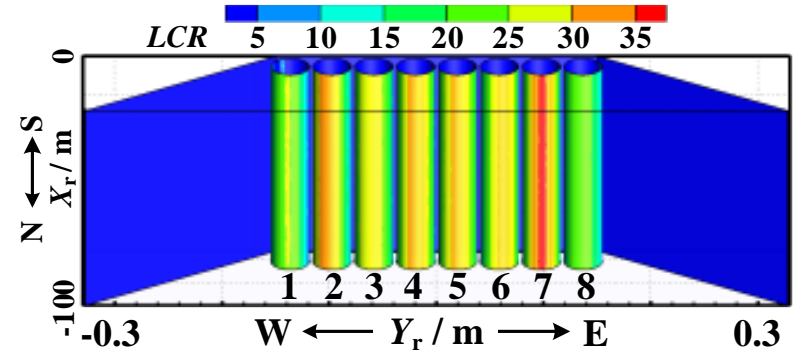

(a) S2 with $n_{\text {aim }}=5: W_{\text {aim }}=232 \mathrm{~mm}, f_{\mathrm{MT}}=0.07$, $L C R_{\max }=36.3, \eta_{\mathrm{opt}}=66.0 \%$

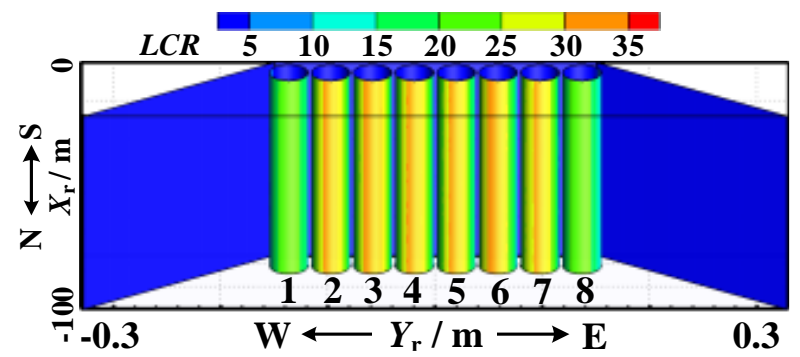

(c) S2 with $n_{\text {aim }}=9: W_{\text {aim }}=242 \mathrm{~mm}, f_{\mathrm{MT}}=0.06$, $L C R_{\max }=34.2, \eta_{\mathrm{opt}}=66.0 \%$

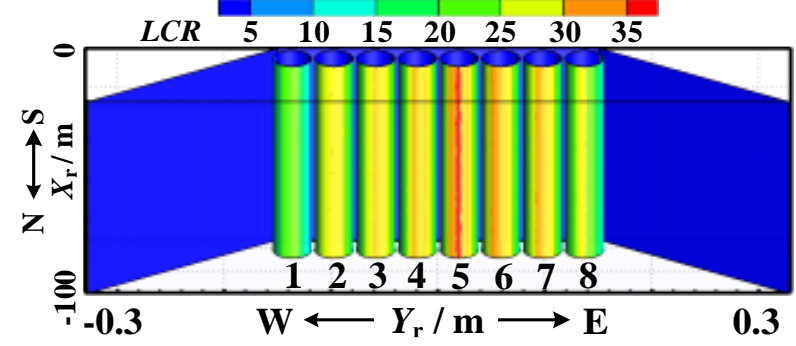

(b) S2 with $n_{\text {aim }}=7: W_{\text {aim }}=242 \mathrm{~mm}, f_{\mathrm{MT}}=0.07$, $L C R_{\max }=35.8, \eta_{\mathrm{opt}}=66.0 \%$

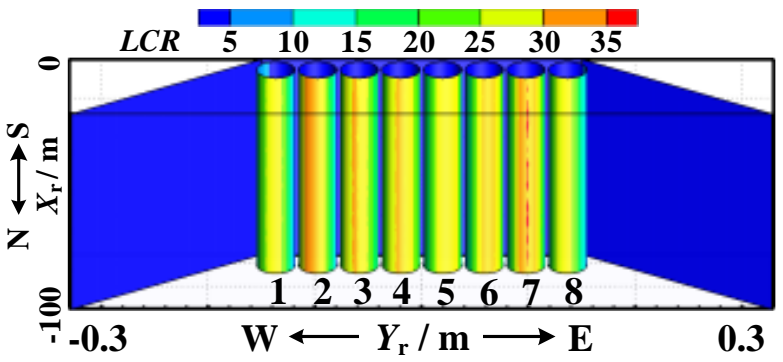

(d) S2 with $n_{\text {aim }}=19: W_{\text {aim }}=300 \mathrm{~mm}, f_{\mathrm{MT}}=0.04$,

$$
L C R_{\max }=35.4, \eta_{\mathrm{opt}}=66.2 \%
$$

Fig. 11. Optimal flux distributions in MTCR at different aiming line numbers $\left(n_{\text {aim }}\right)$ when $\alpha_{\mathrm{s}, \mathrm{T}}=\alpha_{\mathrm{s}}=45^{\circ}$ and $A_{\mathrm{s}}=90^{\circ}$.

Fig. 12 shows the $L C R$ distributions in the STRSC at different aiming line numbers $\left(n_{\text {aim }}\right)$. It is seen that the optimal result of $W_{\text {aim }}$ varies with $n_{\text {aim. }}$ It is also seen that the influence of $n_{\text {aim }}$ on the optical efficiency is insignificant when $n_{\text {aim }}=5 \sim 19$. However, decreasing trends of $f_{\text {st }}$ and $L C R \max$ 
with increasing $n_{\text {aim }}$ can be observed when $n_{\text {aim }}=5 \sim 11$. This is because that the rays on the absorber can be dispersed in a better way when more aiming lines are adopted. Furthermore, it is found that $f_{\mathrm{st}}$ and $L C R_{\max }$ change little when $n_{\text {aim }}=11 \sim 19$, and they remain at about 0.34 and 61 , respectively. From above results, it can be concluded that $n_{\text {aim }}$ should be large enough, which is necessary for obtaining a uniform flux distribution in the STRSC. In current STRSC, $n$ aim of 11 is suggested.

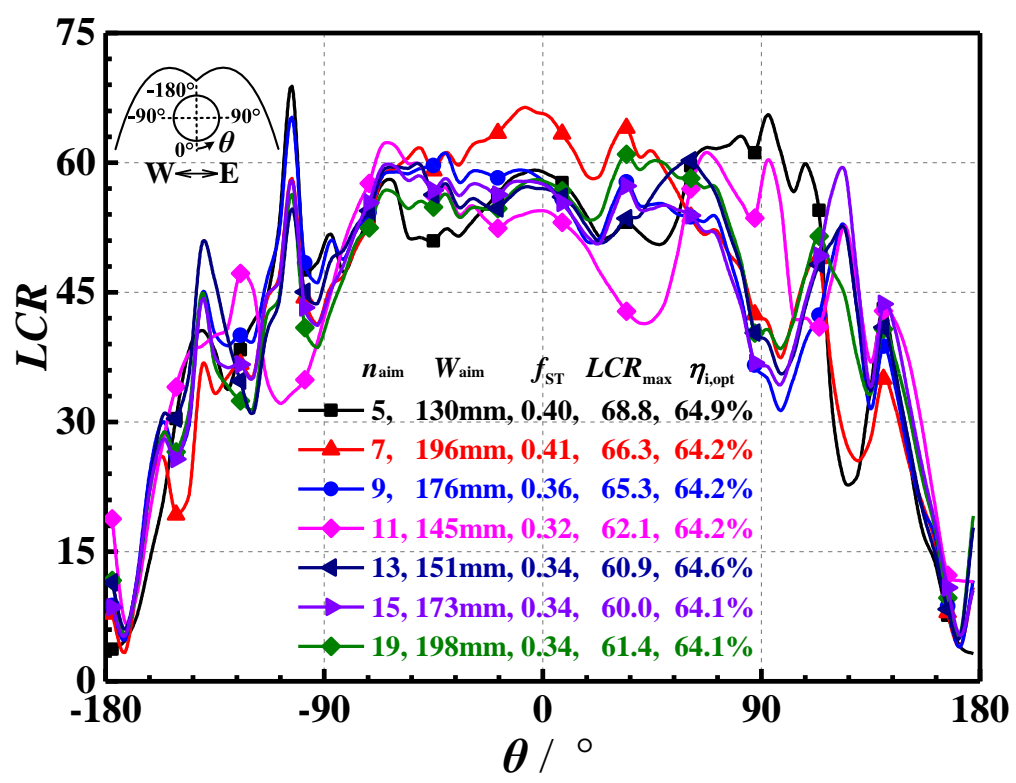

Fig. 12. Optimal flux profiles in STRSC at different aiming line numbers $\left(n_{\text {aim }}\right)$ when $\alpha_{\mathrm{s}, \mathrm{T}}=\alpha_{\mathrm{s}}=45^{\circ}$ and $A_{\mathrm{s}}=90^{\circ}$.

\subsubsection{Employment of an optimal solution in a range of transversal incident angle}

It is well known that the mirrors will track the sun during operation, and the time between two tracking actions is usually in the range of several seconds to several minutes, which is very short. Therefore, if the aiming strategy optimization was implemented at each tracking step, which has a corresponding transversal incidence angle $\left(\alpha_{\mathrm{s}, \mathrm{T}}\right)$, there would be too many optimization cases. As a result, the computation time would be huge. For reducing the computation time, a probable method is to use the optimal solution obtained at a specific $\alpha_{\mathrm{s}, \mathrm{T}}$ in a reasonable large angle range around this specific $\alpha_{\mathrm{s}, \mathrm{T}}$.

For the current two LFRs, the optimal solutions obtained at $\alpha_{\mathrm{s}, \mathrm{T}}=45^{\circ}$ are tested under other

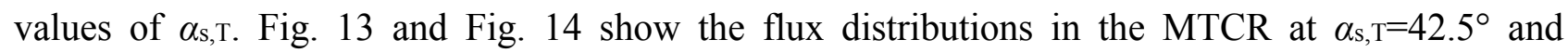
$\alpha_{\mathrm{s}, \mathrm{T}}=47.5^{\circ}$, respectively. It is presented in Fig. 13(b) and Fig. 14(b) that uniform fluxes in the MTCR can still be obtained by S2, and the $f_{\mathrm{MT}}$ of 0.04 is achieved at two angles. The drops in $f_{\mathrm{MT}}$ are both 96\% compared with those of S1 in Fig. 13(a) and Fig. 14(a). Moreover, the drops in the efficiency of S2 are both 1.9 percentage points compared with those of S1. 


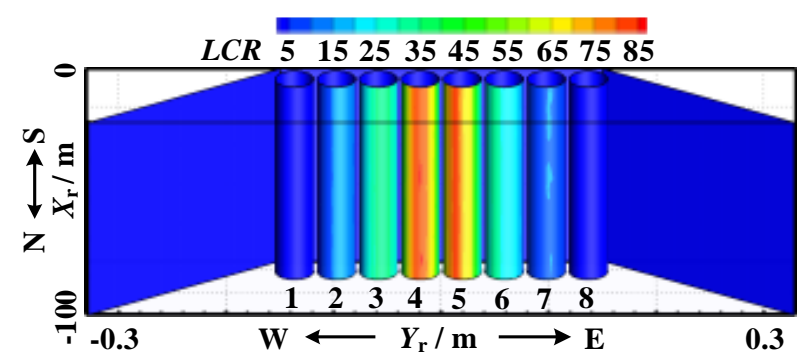

(a) S1: $f_{\mathrm{MT}}=0.99, L C R_{\max }=86.0, \eta_{\mathrm{opt}}=67.9 \%$.

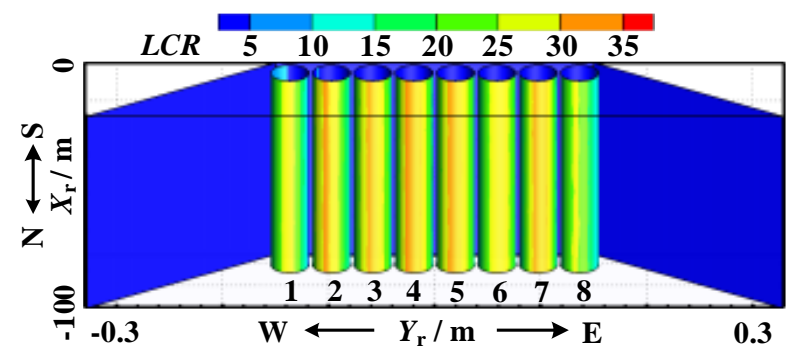

(b) S2 with $n_{\text {aim }}=11$ and $W_{\text {aim }}=255 \mathrm{~mm}: f_{\mathrm{MT}}=0.04$, $L C R_{\max }=34.5, \eta_{\mathrm{opt}}=66.0 \%$

Fig. 13. Comparison of flux distributions in MTCR between two aiming strategies when $\alpha_{\mathrm{s}, \mathrm{T}}=\alpha_{\mathrm{s}}=42.5^{\circ}$ and $A_{\mathrm{s}}=90^{\circ}$.

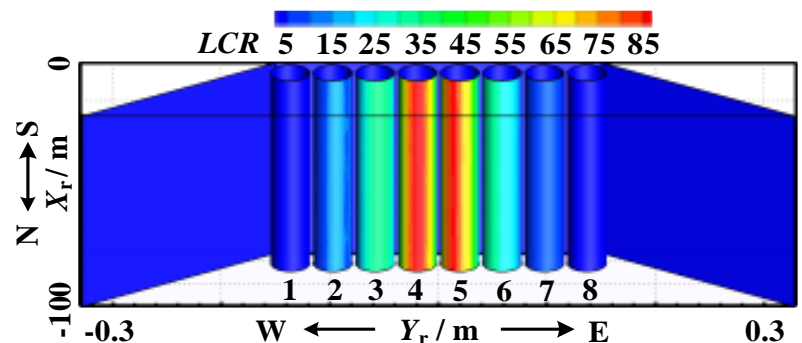

(a) S1: $f_{\mathrm{MT}}=1.02, L C R_{\max }=90.0, \eta_{\mathrm{opt}}=70.0 \%$.

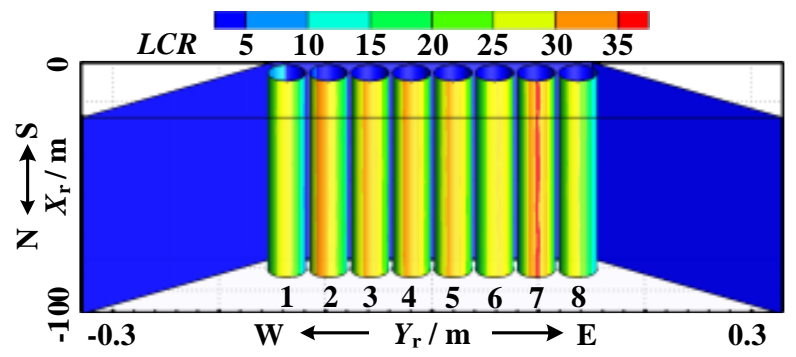

(b) S2 with $n_{\text {aim }}=11$ and $W_{\text {aim }}=255 \mathrm{~mm}: f_{\mathrm{MT}}=0.04$,

$$
L C R_{\max }=36.4, \eta_{\mathrm{opt}}=68.1 \%
$$

Fig. 14. Comparison of flux distributions in MTCR between two aiming strategies when $\alpha_{\mathrm{s}, \mathrm{T}}=\alpha_{\mathrm{s}}=47.5^{\circ}$ and $A_{\mathrm{s}}=90^{\circ}$.

Fig. 15 shows the flux profiles in the STRSC for two aiming strategies at $\alpha_{\mathrm{s}, \mathrm{T}}=42.5^{\circ}$ and $\alpha_{\mathrm{s}, \mathrm{T}}=47.5^{\circ}$. It is seen that the optimal solution at $\alpha_{\mathrm{s}, \mathrm{T}}=45^{\circ}$ can still obtain uniform fluxes at $\alpha_{\mathrm{s}, \mathrm{T}}=42.5^{\circ}$ and $\alpha_{\mathrm{s}, \mathrm{T}}=47.5^{\circ}$. It is also seen that the flux profiles for both $\mathrm{S} 1$ and $\mathrm{S} 2$ change little when $\alpha_{\mathrm{s}, \mathrm{T}}$ increases from $42.5^{\circ}$ to $\alpha_{\mathrm{s}, \mathrm{T}}=47.5^{\circ}$. This is because the incident rays from the mirrors vary little within this small range of $5^{\circ}$ for $\alpha_{\mathrm{s}, \mathrm{T}}$.

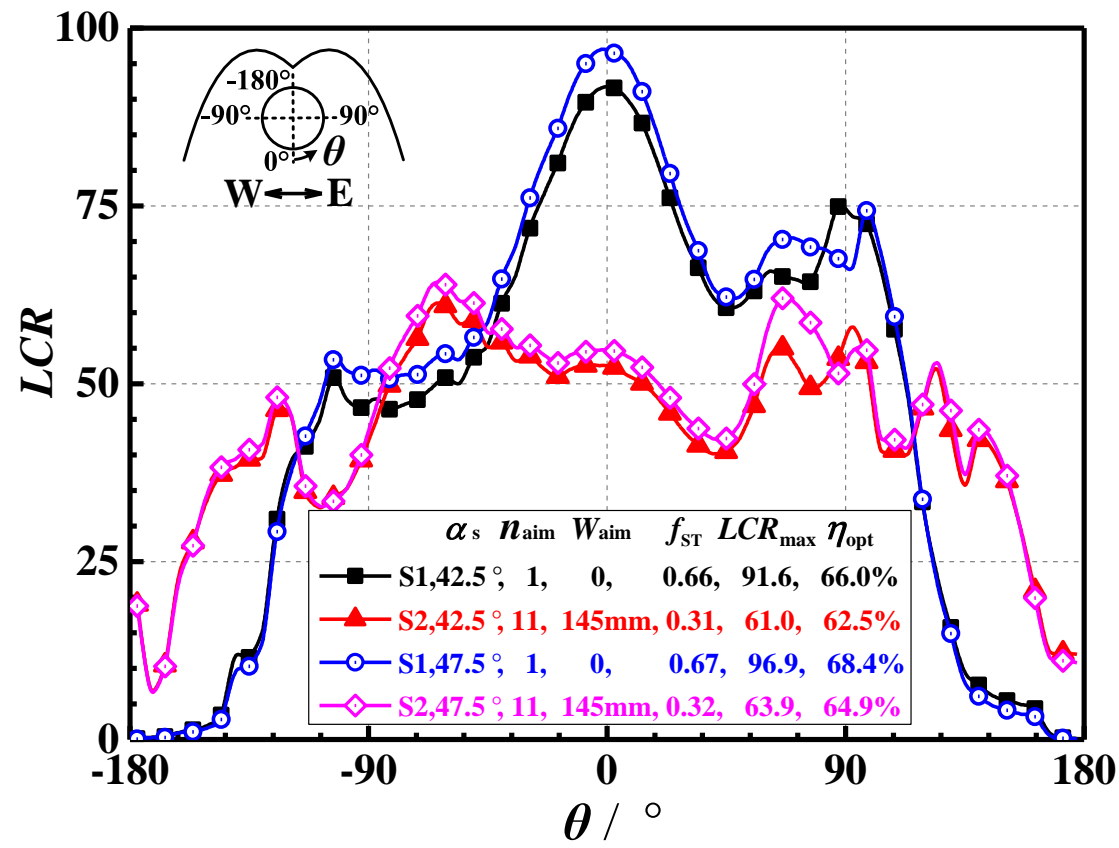

Fig. 15. Comparison of flux profiles in STRSC between two aiming strategies at different $\alpha_{\mathrm{s}, \mathrm{T}}$ when $A_{\mathrm{S}}=90^{\circ}$. 
In addition, another 16 cases given in the first two columns in Table 3 are also examined. The angle interval of $\alpha_{\mathrm{S}, \mathrm{T}}$ between two adjacent cases is $5^{\circ}$. Results which are similar to those above are found as well. It is found that each optimal solution which is obtained at a specific $\alpha_{\mathrm{s}, \mathrm{T}}$ for each case

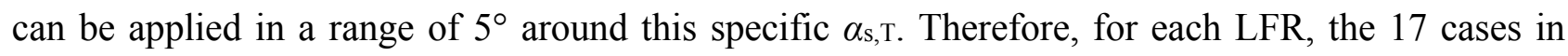
Table 3 can obtain the uniform fluxes in the whole range of $\alpha_{\mathrm{s}, \mathrm{T}}=10^{\circ} \sim 90^{\circ}$. As a result, the number of the optimization cases and the computation time are greatly reduced. Detailed discussion of the 17 cases will be conducted in section 5.2 .

\subsection{Application of GA optimization strategy under a real-time condition}

It is important for an aiming strategy to obtain sufficiently good results at any time rather than just a specific time point. So, 17 key cases given in the first two columns in Table 3 are used to cover the whole ranges of the time and the transversal incidence angle. The procedures for implementing the GA optimization strategy (S2) are detailed as follows.

First, aiming strategies for the 17 key cases with different values of $\alpha_{\mathrm{s}, \mathrm{T}, i}$ are optimized using S2 when $A_{\mathrm{s}}=90^{\circ}$, where $i$ is the ordinal number of the cases in Table 3 . The optimal solutions for the MTCR and STRSC systems are given in the Appendix. Second, the $\alpha_{\mathrm{s}, \mathrm{T}}\left(t_{\mathrm{s}}\right)$ at each possible time point $\left(t_{\mathrm{s}}\right)$ in a year will be calculated for each LFR. If Eq.(18) is satisfied, the optimal solution of case $i$ will be selected as the aiming strategy at $t_{\mathrm{s}}$. Third, the tracking angles of the mirrors at $t_{\mathrm{s}}$ will be calculated using Eq.(7). Finally, the tracking angles at all possible yearly time points will be calculated in advance and stored in the computer of the tracking system to drive the mirrors.

$$
\left|\alpha_{\mathrm{s}, \mathrm{T}}\left(t_{\mathrm{s}}\right)-\alpha_{\mathrm{s}, \mathrm{T}, i}\right| \leq 2.5^{\mathrm{o}}
$$

In the following paragraphs, the GA strategy (S2) is applied in both the MTCR and STRSC systems on spring equinox to illustrate the application of S2 under a real-time condition, where the LFR is assumed to be located at the latitude of $\varphi=\mathrm{N} 23.5^{\circ}$. And 17 time points given in the last three columns in Table 3 are studied, where the incident ray at the $i$ th time point has the same $\alpha_{\mathrm{s}, \mathrm{T}}$ as that of case $i$. 
Table 3. Seventeen cases and corresponding time points on spring equinox.

\begin{tabular}{crrrr}
\hline Case $i$ & $\alpha_{\mathrm{s}, \mathrm{T}, i} /{ }^{\circ}$ & $t_{\mathrm{s}} / \mathrm{h}$ & $A_{\mathrm{s}} /{ }^{\circ}$ & $\alpha_{\mathrm{s}} /^{\circ}$ \\
\hline 1 & 10.0 & 6.716 & 94.0 & 10.0 \\
2 & 15.0 & 7.076 & 96.3 & 14.9 \\
3 & 20.0 & 7.434 & 98.6 & 19.8 \\
4 & 25.0 & 7.788 & 101.0 & 24.6 \\
5 & 30.0 & 8.138 & 103.7 & 29.3 \\
6 & 35.0 & 8.482 & 106.5 & 33.9 \\
7 & 40.0 & 8.822 & 109.6 & 38.3 \\
8 & 45.0 & 9.158 & 113.0 & 42.6 \\
9 & 50.0 & 9.488 & 116.9 & 46.8 \\
10 & 55.0 & 9.814 & 121.3 & 50.7 \\
11 & 60.0 & 10.136 & 126.4 & 54.4 \\
12 & 65.0 & 10.452 & 132.4 & 57.7 \\
13 & 70.0 & 10.766 & 139.5 & 60.7 \\
14 & 75.0 & 11.078 & 147.9 & 63.3 \\
15 & 80.0 & 11.386 & 157.5 & 65.2 \\
16 & 85.0 & 11.694 & 168.4 & 66.5 \\
17 & 90.0 & 12.000 & 180.0 & 66.9 \\
\hline
\end{tabular}

\subsubsection{Application in an LFR with an MTCR}

Fig. 16 shows the optimal result of S2 and the corresponding result of S1 in the MTCR system at different time in the morning on spring equinox, where the symmetrical results in the afternoon are omitted. Fig. 17 and Fig. 18 illustrate the typical real-time solar fluxes in the MTCR when S1 and S2 are used, respectively.

It is seen in Fig. 16 that $f_{\mathrm{MT}}$ is greatly reduced from $0.77 \sim 1.09$ when $\mathrm{S} 1$ is used to $0.02 \sim 0.06$ when S2 is used in the whole range of time. It is also seen in Fig. 17 that hot regions appear on tubes 5 and 6 when S1 is used, while this phenomenon is eliminated by S2 as shown in Fig. 18. In Fig. 17 and Fig. 18, it is visually observed that the southern ends of the tubes are barely shone. Because the rays generally come from the south, and the rays reflected by the southern ends of the mirrors will not hit the southern ends of the MTCR, which leads to this end loss. Moreover, it is observed in Fig. 16 that the maximum flux $\left(q_{1, \max }\right)$ is reduced from $10.0 \sim 92.8 \mathrm{~kW} \cdot \mathrm{m}^{-2}$ when $\mathrm{S} 1$ is used to $4.6 \sim 38.6$ $\mathrm{kW} \cdot \mathrm{m}^{-2}$ with the adoption of S2. Finally, it can be found that a small drop of $1.0 \sim 3.5$ percentage points in $\eta_{\mathrm{opt}}$ can be found when $\mathrm{S} 1$ is replaced by $\mathrm{S} 2$. 


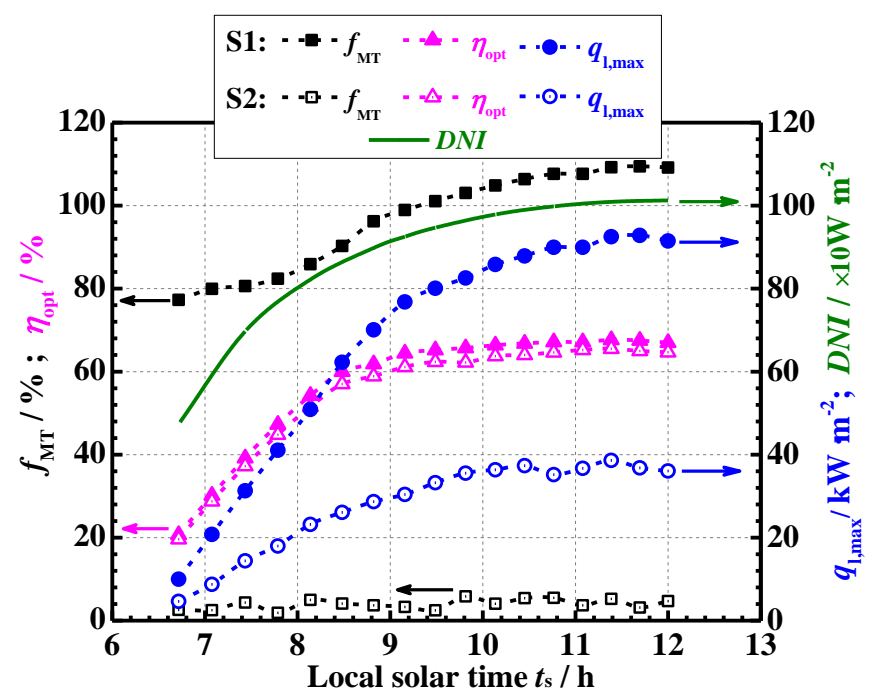

Fig. 16. Optimal result of S2 and the result of S1 in the MTCR system on spring equinox.

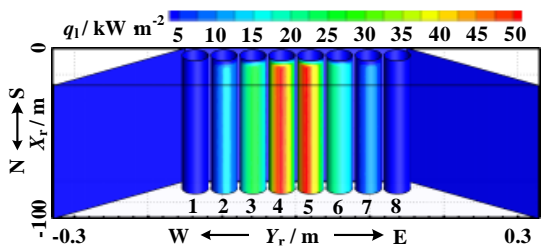

(a) $t_{\mathrm{s}}=8.138 \mathrm{~h}: f_{\mathrm{MT}}=0.86, q_{1, \max }=50.9$ $\mathrm{kW} \cdot \mathrm{m}^{-2}, \eta_{\mathrm{opt}}=54.2 \%$.

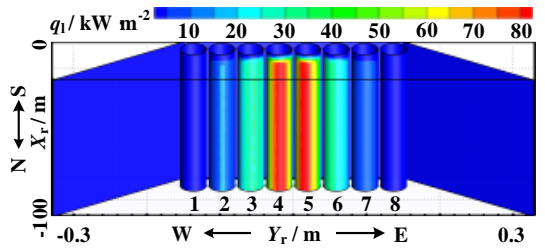

(b) $t_{\mathrm{s}}=10.136 \mathrm{~h}: f_{\mathrm{MT}}=1.05, q_{1, \max }=85.8$

$\mathrm{kW} \cdot \mathrm{m}^{-2}, \eta_{\mathrm{opt}}=66.4 \%$.

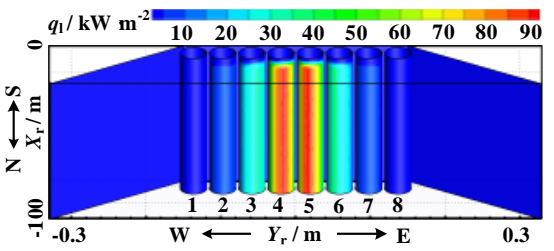

(c) $t_{\mathrm{s}}=12 \mathrm{~h}: f_{\mathrm{MT}}=1.09, q_{1, \max }=91.5$ $\mathrm{kW} \cdot \mathrm{m}^{-2}, \eta_{\mathrm{opt}}=67.0 \%$.

Fig. 17. Real-time flux distributions in MTCR on spring equinox when S1 is used.

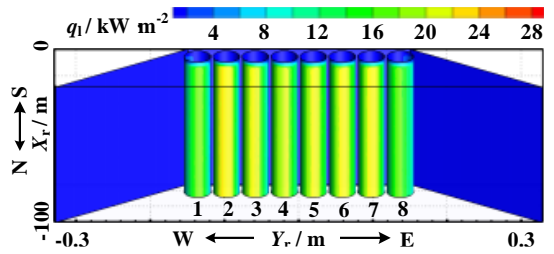

(a) $t_{\mathrm{s}}=8.138 \mathrm{~h}: W_{\text {aim }}=242 \mathrm{~mm}, f_{\mathrm{MT}}=0.05$, $q_{1, \max }=23.2 \mathrm{~kW} \cdot \mathrm{m}^{-2}, \eta_{\mathrm{opt}}=51.5 \%$.

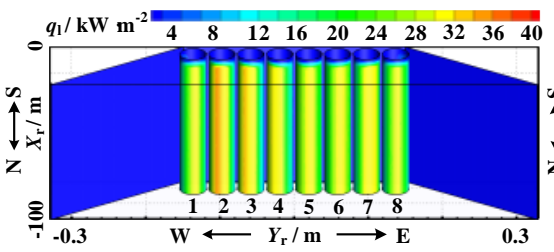

(b) $t_{\mathrm{s}}=10.136 \mathrm{~h}: W_{\mathrm{aim}}=247 \mathrm{~mm}, f_{\mathrm{MT}}=0.04$, $q_{1, \max }=36.3 \mathrm{~kW} \cdot \mathrm{m}^{-2}, \eta_{\mathrm{opt}}=63.7 \%$.

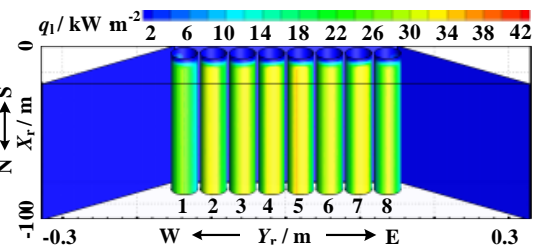

(c) $t_{\mathrm{s}}=12 \mathrm{~h}: W_{\mathrm{aim}}=245 \mathrm{~mm}, \quad f_{\mathrm{MT}}=0.05$, $q_{1, \max }=36.1 \mathrm{~kW} \cdot \mathrm{m}^{-2}, \eta_{\mathrm{opt}}=64.7 \%$.

Fig. 18. Real-time flux distributions in MTCR on spring equinox when $\mathrm{S} 2$ is used.

\subsubsection{Application in an LFR with an STRSC}

Fig. 19 shows the optimal result of S2 and the corresponding result of S1 in the STRSC system on the spring equinox. Fig. 20 and Fig. 21 illustrate the typical real-time solar fluxes in the STRSC when S1 and S2 are used, respectively, where the end loss caused by the nonzero incident angle can also be observed. Fig. 22 shows the comparison of the detailed flux profiles on the absorber.

It is seen in Fig. 19 that $f_{\mathrm{ST}}$ is reduced from $0.59 \sim 0.70$ when $\mathrm{S} 1$ is used to $0.29 \sim 0.37$ with the adoption of S2. It is found in Fig. 20 and Fig. 22 that hot regions occur at the bottom of the absorber when S1 is used, and the top half of the absorber is barely used. However, the hot spots are 
efficiently weakened by S2 as shown in Fig. 21 and Fig. 22, and it is observed in Fig. 19 that the maximum flux is reduced from $12.1 \sim 101.2 \mathrm{~kW} \cdot \mathrm{m}^{-2}$ when $\mathrm{S} 1$ is used to $9.9 \sim 69.6 \mathrm{~kW} \cdot \mathrm{m}^{-2}$ with the adoption of S2. Moreover, it is found that the solar power is distributed quite well around the tube for each case, and about $35 \sim 40 \%$ of total power is shone on the top half of the tube. Finally, it is seen that a small decrease of $0.2 \sim 3.8$ percentage points in $\eta_{\mathrm{opt}}$ is found when S1 is replaced by S2.

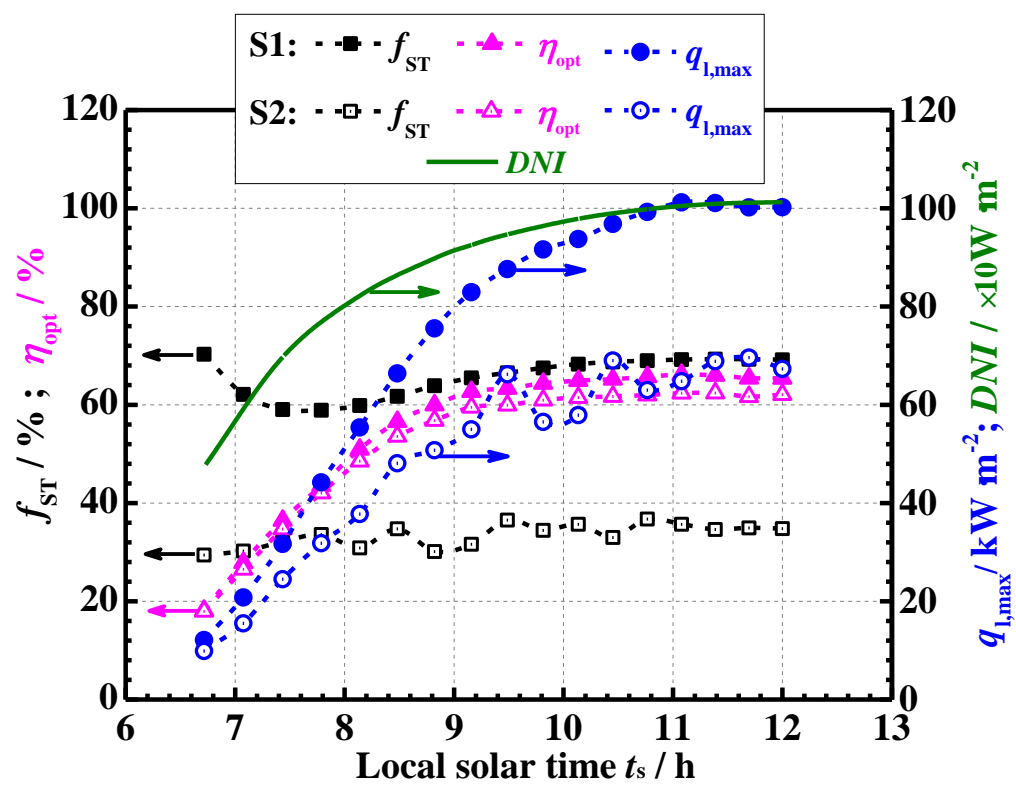

Fig. 19. Optimal result of S2 and the result of S1 in the STRSC system on spring equinox.

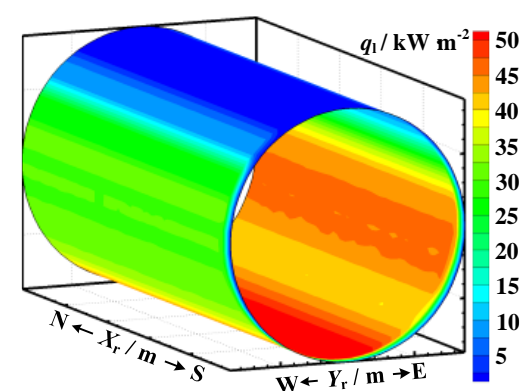

(a) $t_{\mathrm{s}}=8.138 \mathrm{~h}: \quad f_{\mathrm{ST}}=0.60, q_{1, \max }=54.5$

$\mathrm{kW} \cdot \mathrm{m}^{-2}, \eta_{\mathrm{opt}}=50.9 \%$

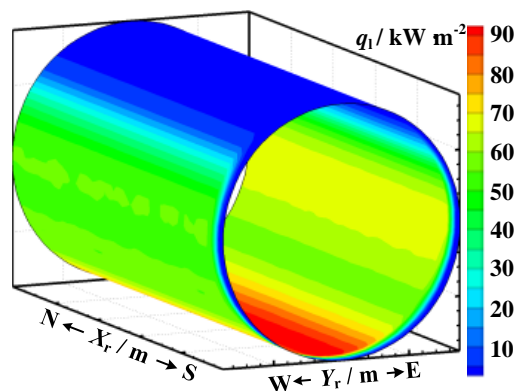

(b) $t_{\mathrm{s}}=10.136 \mathrm{~h}: f_{\mathrm{sT}}=0.68, q_{1, \max }$ $=93.7 \mathrm{~kW} \cdot \mathrm{m}^{-2}, \eta_{\mathrm{opt}}=64.9 \%$

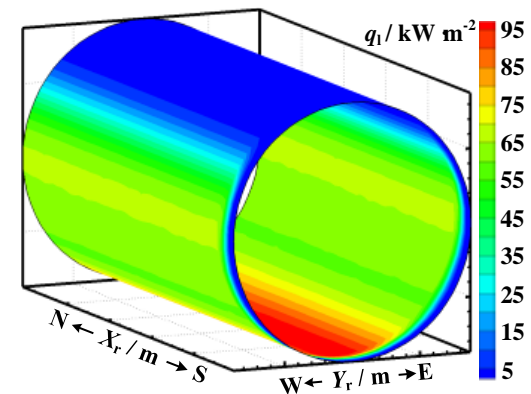

(c) $t_{\mathrm{s}}=12 \mathrm{~h}: \quad f_{\mathrm{ST}}=0.69, q_{1, \max }=99.0$ $\mathrm{kW} \cdot \mathrm{m}^{-2}, \eta_{\mathrm{opt}}=65.4 \%$

Fig. 20. Real-time flux distributions in STRSC on spring equinox when S1 is used.

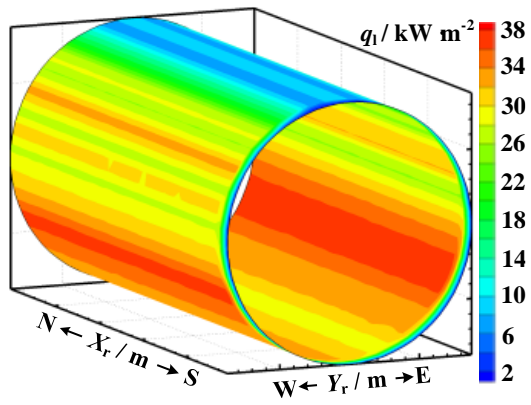

(a) $t_{\mathrm{s}}=8.138 \mathrm{~h}: W_{\mathrm{aim}}=135 \mathrm{~mm}, f_{\mathrm{ST}}=0.31$, $q 1, \max =37.7 \mathrm{~kW} \cdot \mathrm{m}^{-2}, \eta_{\mathrm{opt}}=48.5 \%$

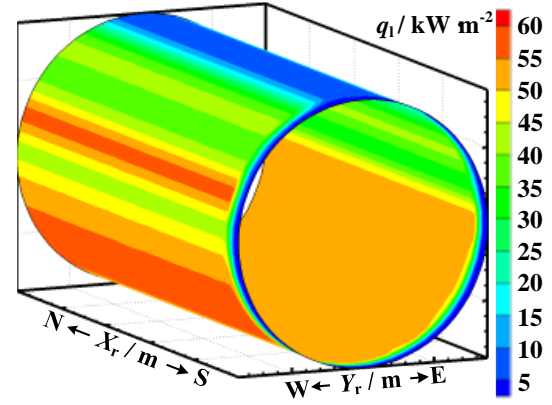

(b) $t_{\mathrm{s}}=10.136 \mathrm{~h}: W_{\mathrm{aim}}=154 \mathrm{~mm}, f_{\mathrm{ST}}=0.36$, $q 1, \max =57.9 \mathrm{~kW} \cdot \mathrm{m}^{-2}, \eta_{\mathrm{opt}}=61.5 \%$

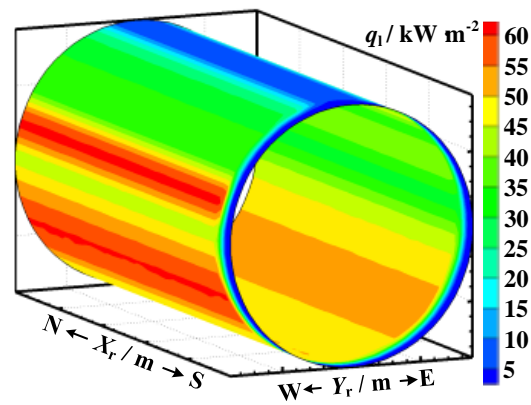

(c) $t_{\mathrm{s}}=12 \mathrm{~h}: W_{\text {aim }}=201 \mathrm{~mm}, f_{\mathrm{ST}}=0.35, q_{1, \max }$ $=67.3 \mathrm{~kW} \cdot \mathrm{m}^{-2}, \eta_{\mathrm{opt}}=62.1 \%$

Fig. 21. Real-time flux distributions in STRSC on spring equinox when $\mathrm{S} 2$ is used. 


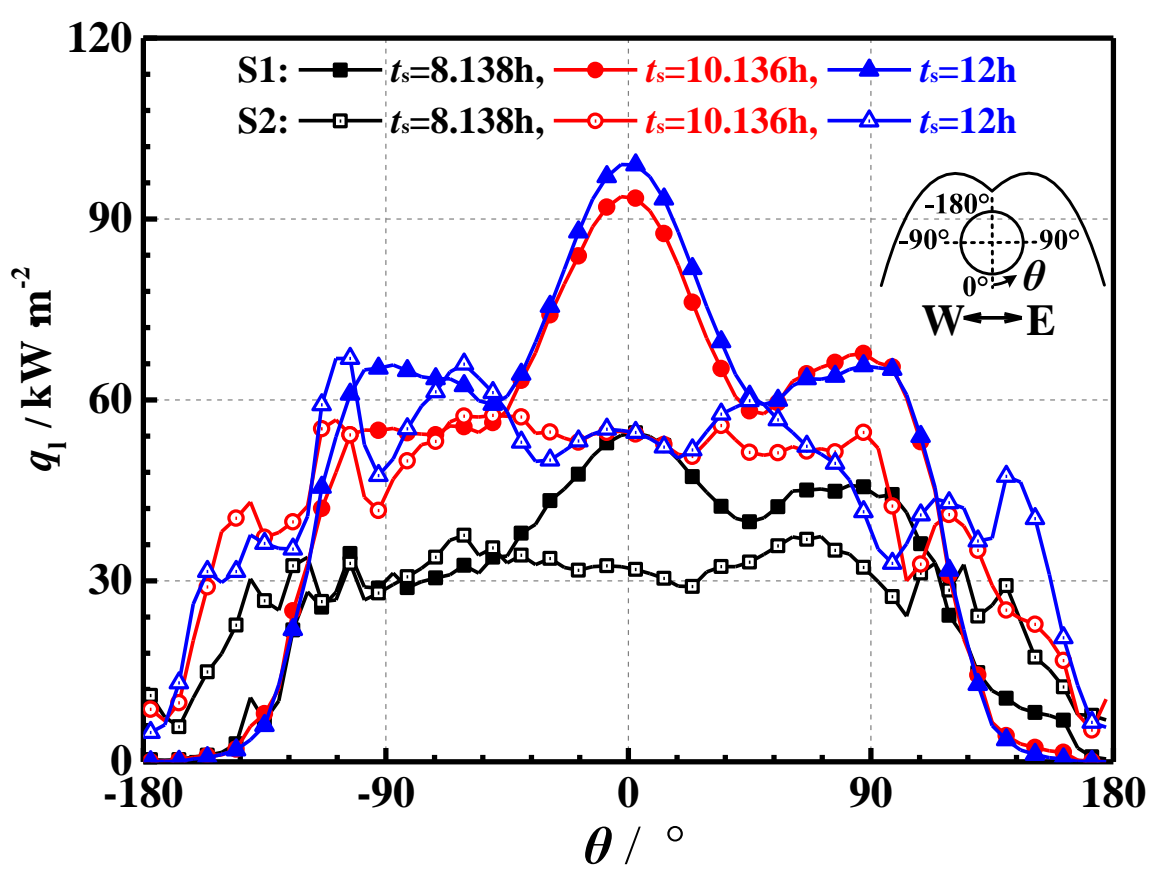

Fig. 22. Real-time flux profiles in STRSC on spring equinox when S1 and S2 are used.

\section{Conclusions}

This work presents an aiming strategy optimization approach for homogenizing the flux distributions in both the Multi-Tube Cavity Receiver (MTCR) and the Single-Tube Receiver with a Secondary Collector (STRSC) in linear Fresnel reflectors (LFRs). In the approach, the fluxes are computed using an MCRT model, and the optimization is conducted based on a multi-objective GA. The MCRT model was validated against both experimental and simulation data. The following conclusions are derived.

(1) Comparison of the typical flux distributions between traditional one-line strategy (S1) and the present GA optimization strategy (S2) indicate that a compromise between the flux non-uniformity and the optical efficiency can be reached by S2 in both MTCR and STRSC systems. Moreover, the optimal solution obtained at a specific value of the transversal incidence angle $\left(\alpha_{\mathrm{s}, \mathrm{T}}\right)$ can be applied in a relatively large range (e.g., $5^{\circ}$ ) around it.

(2) The number of aiming lines has almost no effect on the optical efficiency and the flux non-uniformity in the MTCR system. For the STRSC system, $n_{\text {aim }}$ has almost no effect on the efficiency, but it has a visible effect on the flux non-uniformity. It is found that a sufficiently large $n_{\text {aim }}$ is necessary for obtaining uniform fluxes in the STRSC.

(3) Under a real-time condition, application of the GA approach indicates that the flux distributions in both the MTCR and the STRSC can be homogenized efficaciously in the whole 
range of the incident angle by the GA approach with a small drop of around $0.2 \sim 3.8$ percentage points in efficiency compared with those of S1. It is found that the non-uniformity index for the MTCR system is greatly reduced from $0.77 \sim 1.09$ to $0.02 \sim 0.06$, and the maximum flux is reduced from $10.0 \sim 92.8 \mathrm{~kW} \cdot \mathrm{m}^{-2}$ to $4.6 \sim 38.6 \mathrm{~kW} \cdot \mathrm{m}^{-2}$ when $\mathrm{S} 2$ replaces $\mathrm{S} 1$. For the STRSC system, the non-uniformity index is decreased from $0.59 \sim 0.70$ to $0.29 \sim 0.37$, and the maximum flux is decreased from $12.1 \sim 101.2 \mathrm{~kW} \cdot \mathrm{m}^{-2}$ to $9.9 \sim 69.6 \mathrm{~kW} \cdot \mathrm{m}^{-2}$ when $\mathrm{S} 2$ replaces $\mathrm{S} 1$.

In conclusion, these results indicate that the present GA approach is effective and suitable for optimizing the flux distributions in the receivers of LFRs, which can be beneficial for the further studies and the industrial application.

\section{Acknowledgements}

The study is supported by the Key Project of National Natural Science Foundation of China (No.51436007) and the Foundation for Innovative Research Groups of the National Natural Science Foundation of China (No. 51721004).

The authors would also like to thank the Innovative Talents Support Plan of China Postdoctoral Foundation.

\section{Appendix}

The optimal solutions of the aiming strategies under seventeen key cases for the MTCR and STRSC systems are given in Table 1 and Table 2 , respectively. In the optimization, $n_{\text {aim }}=11$. 
Table 1. Optimal solutions of the MTCR system for seventeen key cases.

\begin{tabular}{|c|c|c|c|c|c|c|c|c|c|c|c|c|c|c|c|c|c|c|c|c|c|c|c|c|c|c|}
\hline Case $i$ & $g_{1}$ & $g_{2}$ & $g_{3}$ & $g_{4}$ & $g_{5}$ & $g_{6}$ & $g_{7}$ & $g_{8}$ & $g_{9}$ & $g_{10}$ & $g_{11}$ & $g_{12}$ & $g_{13}$ & $g_{14}$ & $g_{15}$ & $g_{16}$ & $g_{17}$ & $g_{18}$ & $g_{19}$ & $g_{20}$ & $g_{21}$ & $g_{22}$ & $g_{23}$ & $g_{24}$ & $g_{25}$ & $g_{26}$ \\
\hline 1 & 4 & 9 & 2 & 6 & 4 & 1 & 3 & $\overline{9}$ & 1 & $\overline{6}$ & 1 & 4 & 6 & 10 & 2 & 8 & 8 & 7 & 3 & 7 & 4 & 2 & 3 & 5 & 2 & $291 \mathrm{~mm}$ \\
\hline 2 & 4 & 10 & 2 & 6 & 7 & 2 & 1 & 10 & 1 & 4 & 1 & 3 & 6 & 10 & 6 & 8 & 8 & 9 & 2 & 8 & 4 & 3 & 4 & 7 & 5 & $260 \mathrm{~mm}$ \\
\hline 3 & 4 & 4 & 3 & 8 & 10 & 3 & 8 & 1 & 10 & 9 & 10 & 6 & 4 & 2 & 8 & 9 & 5 & 3 & 4 & 3 & 4 & 5 & 6 & 6 & 9 & $292 \mathrm{~mm}$ \\
\hline 4 & 4 & 3 & 9 & 6 & 2 & 4 & 1 & 11 & 6 & 9 & 1 & 11 & 2 & 4 & 8 & 7 & 9 & 9 & 2 & 8 & 7 & 6 & 6 & 7 & 8 & $260 \mathrm{~mm}$ \\
\hline 5 & 10 & 7 & 9 & 1 & 10 & 6 & 4 & 4 & 1 & 11 & 1 & 1 & 2 & 11 & 8 & 6 & 3 & 9 & 9 & 9 & 10 & 8 & 5 & 3 & 5 & $242 \mathrm{~mm}$ \\
\hline 6 & 10 & 7 & 9 & 1 & 7 & 5 & 5 & 4 & 1 & 11 & 1 & 1 & 2 & 10 & 10 & 6 & 3 & 10 & 9 & 9 & 10 & 9 & 7 & 3 & 5 & $245 \mathrm{~mm}$ \\
\hline 7 & 10 & 7 & 8 & 1 & 7 & 5 & 4 & 1 & 5 & 11 & 1 & 1 & 2 & 11 & 8 & 11 & 4 & 9 & 9 & 9 & 9 & 8 & 6 & 4 & 5 & $246 \mathrm{~mm}$ \\
\hline 8 & 7 & 10 & 2 & 5 & 1 & 6 & 11 & 2 & 7 & 11 & 1 & 1 & 4 & 10 & 3 & 9 & 6 & 4 & 5 & 9 & 9 & 10 & 5 & 7 & 7 & $255 \mathrm{~mm}$ \\
\hline 9 & 8 & 6 & 9 & 2 & 5 & 5 & 3 & 4 & 5 & 11 & 1 & 1 & 1 & 11 & 7 & 8 & 2 & 10 & 10 & 9 & 9 & 9 & 7 & 4 & 5 & $254 \mathrm{~mm}$ \\
\hline 10 & 9 & 7 & 5 & 1 & 7 & 6 & 4 & 4 & 4 & 10 & 1 & 1 & 3 & 11 & 7 & 8 & 1 & 9 & 11 & 11 & 10 & 9 & 6 & 3 & 5 & $256 \mathrm{~mm}$ \\
\hline 11 & 10 & 6 & 5 & 3 & 7 & 6 & 3 & 4 & 4 & 11 & 1 & 1 & 1 & 11 & 8 & 7 & 2 & 11 & 10 & 10 & 9 & 10 & 4 & 4 & 5 & $247 \mathrm{~mm}$ \\
\hline 12 & 9 & 6 & 8 & 2 & 6 & 5 & 4 & 4 & 3 & 10 & 1 & 1 & 2 & 11 & 7 & 7 & 1 & 10 & 11 & 11 & 9 & 9 & 6 & 4 & 5 & $253 \mathrm{~mm}$ \\
\hline 13 & 9 & 8 & 7 & 2 & 7 & 6 & 4 & 4 & 3 & 11 & 1 & 1 & 1 & 11 & 7 & 8 & 3 & 11 & 10 & 10 & 10 & 9 & 5 & 3 & 5 & $251 \mathrm{~mm}$ \\
\hline 14 & 8 & 7 & 8 & 3 & 6 & 6 & 3 & 4 & 1 & 11 & 1 & 1 & 1 & 11 & 11 & 8 & 3 & 10 & 10 & 6 & 10 & 8 & 6 & 4 & 5 & $252 \mathrm{~mm}$ \\
\hline 15 & 8 & 6 & 7 & 2 & 5 & 5 & 2 & 4 & 4 & 11 & 1 & 1 & 1 & 11 & 7 & 8 & 1 & 10 & 10 & 10 & 10 & 9 & 6 & 4 & 5 & $248 \mathrm{~mm}$ \\
\hline 16 & 3 & 7 & 7 & 2 & 6 & 5 & 2 & 4 & 5 & 11 & 1 & 2 & 1 & 11 & 8 & 8 & 1 & 11 & 11 & 9 & 9 & 10 & 6 & 4 & 4 & $247 \mathrm{~mm}$ \\
\hline 17 & 6 & 4 & 6 & 2 & 2 & 8 & 1 & 1 & 8 & 11 & 6 & 8 & 6 & 11 & 11 & 1 & 10 & 4 & 5 & 3 & 10 & 4 & 9 & 3 & 8 & $245 \mathrm{~mm}$ \\
\hline
\end{tabular}

Table 2. Optimal solutions of the STRSC system for seventeen key cases.

\begin{tabular}{|c|c|c|c|c|c|c|c|c|c|c|c|c|c|c|c|c|c|c|c|c|c|c|c|c|c|c|}
\hline Case $i$ & $g_{1}$ & $g_{2}$ & $g_{3}$ & $g_{4}$ & $g_{5}$ & $g_{6}$ & $g_{7}$ & $g_{8}$ & $g_{9}$ & $g_{10}$ & $g_{11}$ & $g_{12}$ & $g_{13}$ & $g_{14}$ & $g_{15}$ & $g_{16}$ & $g_{17}$ & $g_{18}$ & $g_{19}$ & $g_{20}$ & $g_{21}$ & $g_{22}$ & $g_{23}$ & $g_{24}$ & $g_{25}$ & $g_{26}$ \\
\hline 1 & 9 & 8 & 6 & 3 & 4 & 8 & 1 & 7 & 8 & 4 & 10 & 8 & 1 & 2 & 2 & 7 & 4 & 3 & 1 & 3 & 5 & 4 & 5 & 5 & 8 & $236 \mathrm{~mm}$ \\
\hline 2 & 8 & 5 & 5 & 3 & 7 & 2 & 1 & 1 & 8 & 7 & 2 & 10 & 6 & 6 & 2 & 5 & 3 & 7 & 7 & 7 & 3 & 9 & 4 & 7 & 8 & $189 \mathrm{~mm}$ \\
\hline 3 & 8 & 4 & 7 & 3 & 8 & 1 & 9 & 1 & 1 & 1 & 7 & 7 & 3 & 8 & 7 & 10 & 6 & 3 & 2 & 7 & 5 & 7 & 10 & 5 & 8 & $169 \mathrm{~mm}$ \\
\hline 4 & 9 & 6 & 4 & 6 & 1 & 6 & 7 & 1 & 9 & 8 & 2 & 10 & 2 & 2 & 7 & 3 & 5 & 9 & 10 & 6 & 6 & 2 & 6 & 7 & 5 & $141 \mathrm{~mm}$ \\
\hline 5 & 10 & 7 & 5 & 4 & 5 & 1 & 7 & 8 & 9 & 1 & 2 & 11 & 1 & 10 & 2 & 7 & 7 & 5 & 6 & 9 & 9 & 4 & 4 & 5 & 3 & $135 \mathrm{~mm}$ \\
\hline 6 & 9 & 3 & 7 & 1 & 4 & 8 & 8 & 11 & 3 & 1 & 3 & 6 & 3 & 2 & 10 & 11 & 10 & 2 & 9 & 10 & 5 & 7 & 4 & 7 & 6 & $151 \mathrm{~mm}$ \\
\hline 7 & 7 & 4 & 3 & 6 & 2 & 6 & 7 & 1 & 8 & 1 & 2 & 11 & 4 & 9 & 10 & 10 & 10 & 4 & 6 & 8 & 5 & 7 & 11 & 2 & 4 & $151 \mathrm{~mm}$ \\
\hline 8 & 4 & 3 & 6 & 1 & 7 & 4 & 1 & 8 & 9 & 1 & 7 & 11 & 2 & 3 & 4 & 11 & 9 & 6 & 9 & 10 & 9 & 6 & 4 & 4 & 4 & $145 \mathrm{~mm}$ \\
\hline 9 & 5 & 3 & 2 & 7 & 9 & 6 & 2 & 7 & 2 & 3 & 7 & 7 & 3 & 10 & 8 & 8 & 5 & 7 & 5 & 10 & 3 & 6 & 8 & 10 & 7 & $198 \mathrm{~mm}$ \\
\hline 10 & 10 & 5 & 3 & 4 & 6 & 1 & 7 & 1 & 1 & 9 & 9 & 6 & 5 & 1 & 4 & 10 & 5 & 11 & 2 & 11 & 5 & 8 & 9 & 4 & 5 & $147 \mathrm{~mm}$ \\
\hline 11 & 10 & 5 & 3 & 4 & 6 & 2 & 5 & 1 & 1 & 9 & 8 & 9 & 5 & 2 & 3 & 8 & 4 & 10 & 2 & 11 & 6 & 8 & 9 & 4 & 5 & $154 \mathrm{~mm}$ \\
\hline 12 & 8 & 8 & 7 & 1 & 3 & 10 & 1 & 1 & 9 & 8 & 1 & 8 & 4 & 9 & 11 & 6 & 11 & 2 & 5 & 5 & 11 & 5 & 9 & 3 & 8 & $155 \mathrm{~mm}$ \\
\hline 13 & 10 & 4 & 3 & 4 & 7 & 1 & 5 & 3 & 1 & 9 & 8 & 6 & 5 & 1 & 3 & 9 & 4 & 10 & 2 & 11 & 6 & 8 & 9 & 4 & 5 & $165 \mathrm{~mm}$ \\
\hline 14 & 10 & 4 & 3 & 4 & 8 & 1 & 5 & 1 & 1 & 9 & 9 & 6 & 5 & 1 & 4 & 8 & 3 & 11 & 2 & 11 & 6 & 8 & 9 & 4 & 6 & $159 \mathrm{~mm}$ \\
\hline 15 & 10 & 4 & 3 & 4 & 6 & 1 & 6 & 1 & 1 & 9 & 9 & 6 & 5 & 2 & 4 & 10 & 4 & 11 & 2 & 11 & 6 & 8 & 9 & 4 & 5 & $159 \mathrm{~mm}$ \\
\hline 16 & 10 & 3 & 3 & 4 & 6 & 2 & 5 & 1 & 1 & 9 & 8 & 6 & 5 & 2 & 3 & 10 & 4 & 11 & 2 & 11 & 6 & 8 & 9 & 4 & 5 & $161 \mathrm{~mm}$ \\
\hline 17 & 10 & 8 & 4 & 4 & 2 & 2 & 5 & 7 & 8 & 7 & 2 & 5 & 5 & 4 & 9 & 10 & 4 & 10 & 4 & 5 & 9 & 7 & 7 & 4 & 7 & $201 \mathrm{~mm}$ \\
\hline
\end{tabular}




\section{Nomenclature}

$\begin{array}{ll}A_{\mathrm{s}} & \text { solar azimuth }\left(^{\circ}\right) \\ D N I & \text { Direct Normal Irradiance }\left(\mathrm{W} \cdot \mathrm{m}^{-2}\right) \\ E_{\mathrm{t}} & \text { power absorbed by a tube }(\mathrm{W}) \\ e & \text { power carried by each ray }(\mathrm{W}) \\ f_{\mathrm{ST}} & \text { flux non-uniformity index in STRSC } \\ f_{\mathrm{MT}} & \text { flux non-uniformity index in MTCR } \\ g & \text { individual } \\ g_{i} & \text { gene } \\ H_{\mathrm{t}} & \text { height of absorber tubes }(\mathrm{m}) \\ L C R & \text { local concentration ratio } \\ W_{\mathrm{m}} & \text { length of the mirror }(\mathrm{m}) \\ n_{\mathrm{m}} & \text { number of mirrors } \\ n_{\mathrm{t}} & \text { number of tubes } \\ n_{\mathrm{e}} & \text { number of circumferential elements on tube } \\ n_{\text {aim }} & \text { number of aiming lines } \\ n_{\text {ray,e }} & \text { number of the rays absorbed in local element } \\ n_{\text {ray }} & \text { total number of traced rays } \\ N & \text { size of population } \\ Q & \text { power }(\mathrm{W}) \\ q_{1} & \text { local flux on tube }\left(\mathrm{W} \cdot \mathrm{m}^{-2}\right) \\ R_{\mathrm{m}} & \text { curvature radius of mirror }(\mathrm{m}) \\ r_{1} & \text { outer radius of tube }(\mathrm{mm}) \\ S_{\mathrm{e}} & \text { area of each element }\left(\mathrm{m}^{2}\right) \\ t_{\mathrm{s}} & \text { local solar time }(\mathrm{h}) \\ W_{\text {field }} & \text { width of the field }(\mathrm{m}) \\ W_{\mathrm{m}} & \text { width of the mirror }(\mathrm{m}) \\ X, Y, Z & \text { Cartesian coordinates }(\mathrm{m}) \\ & \end{array}$

\section{Greek symbols}

\begin{tabular}{|c|c|}
\hline$\alpha$ & solar altitude $\left(^{\circ}\right)$ \\
\hline$\alpha_{\mathrm{s}, \mathrm{T}}$ & transversal incidence angle $\left(^{\circ}\right)$ \\
\hline$\eta_{\mathrm{opt}}, \eta_{\text {loss }}$ & optical efficiency/optical loss (\%) \\
\hline$\theta$ & angle on the absorber tube $\left(^{\circ}\right)$ \\
\hline$\theta_{\mathrm{m}}$ & tracking angle $\left({ }^{\circ}\right)$ \\
\hline$\varphi$ & local latitude $\left(^{\circ}\right)$ \\
\hline \multicolumn{2}{|c|}{ Subscripts } \\
\hline $\mathrm{g}, \mathrm{m}, \mathrm{r}, \mathrm{t}$ & glass / mirror / receiver / tube parameter \\
\hline $\max$ & maximum value \\
\hline$i$ & $i$ th parameter \\
\hline $\mathrm{T}$ & transversal parameter \\
\hline s & solar parameter \\
\hline
\end{tabular}




\section{References}

[1] McGlade C, Ekins P. The geographical distribution of fossil fuels unused when limiting global warming to 2 degrees C. Nature. 2015;517:187-90.

[2] Li MJ, Song CX, Tao WQ. A hybrid model for explaining the short-term dynamics of energy efficiency of China's thermal power plants. Appl Energ. 2016;169:738-47.

[3] Yan J. Handbook of clean energy systems Volume 1: Renewable Energy. 1st ed. New York: Wiley; 2015.

[4] Li MJ, Tao WQ. Review of methodologies and polices for evaluation of energy efficiency in high energy-consuming industry. Appl Energ. 2017;187:203-15.

[5] Bellos E, Tzivanidis C, Tsimpoukis D. Multi-criteria evaluation of parabolic trough collector with internally finned absorbers. Appl Energ. 2017;205:540-61.

[6] Li MJ, Tang SZ, Wang FL, Zhao QX, Tao WQ. Gas-side fouling, erosion and corrosion of heat exchangers for middle/low temperature waste heat utilization: A review on simulation and experiment. Appl Therm Eng. 2017;DOI:https://doi.org/10.1016/j.applthermaleng.2017.07.095.

[7] Li MJ, He YL, Tao WQ. Modeling a hybrid methodology for evaluating and forecasting regional energy efficiency in China. Appl Energ. 2017;185:1769-77.

[8] Trancik JE. Renewable energy: Back the renewables boom. Nature. 2014;507:300-2.

[9] Du BC, He YL, Wang K, Zhu HH. Convective heat transfer of molten salt in the shell-and-tube heat exchanger with segmental baffles. Int J Heat Mass Tran. 2017;113:456-65.

[10] Du S, Ren Q, He YL. Optical and radiative properties analysis and optimization study of the gradually-varied volumetric solar receiver. Appl Energ. 2017;DOI:https://doi.org/10.1016/j.apenergy.2017.05.165.

[11] Li L, Sun J, Li Y. Prospective fully-coupled multi-level analytical methodology for concentrated solar power plants: General modelling. Appl Therm Eng. 2017;118:171-87.

[12] Castellani F, Astolfi D, Sdringola P, Proietti S, Terzi L. Analyzing wind turbine directional behavior: SCADA data mining techniques for efficiency and power assessment. Appl Energ. 2017;185:1076-86.

[13] Zhou YP, He YL, Qiu Y, Ren Q, Xie T. Multi-scale investigation on the absorbed irradiance distribution of the nanostructured front surface of the concentrated PV-TE device by a MC-FDTD coupled method. Appl Energ. 2017;https://doi.org/10.1016/j.apenergy.2017.05.115.

[14] Liang Q, He YL, Ren Q. A detailed study on phonon transport in thin silicon membranes with phononic crystal nanostructures. Appl Energ. 2017;DOI:https://doi.org/10.1016/j.apenergy.2017.07.083.

[15] Li YS, Zhao TS. A passive anion-exchange membrane direct ethanol fuel cell stack and its applications. Int J Hydrogen Energ. 2016;41:20336-42.

[16] El-Melih A, Al Shoaibi A, Gupta A. Reformation of hydrogen sulfide to hydrogen in the presence of xylene. Appl Energ. 2017;203:403-11.

[17] Li YS. A liquid-electrolyte-free anion-exchange membrane direct formate-peroxide fuel cell. Int J Hydrogen Energ. 2016;41:3600-4.

[18] Huang D, Song BY, He YL, Ren Q, Yao S. Cations Diffusion in Nafion117 Membrane of Microbial fuel cells. Electrochim Acta. 2017.

[19] Li Y, Feng Y, Sun X, He Y. A Sodium-Ion-Conducting Direct Formate Fuel Cell: Generating Electricity and Producing Base. Angewandte Chemie. 2017;129:5828-31.

[20] Hoffert MI, Caldeira K, Benford G, Criswell DR, Green C, Herzog H, et al. Advanced technology paths to global climate stability energy for a greenhouse planet. Science. 2002;298:981-7.

[21] He YL, Wang K, Du BC, Qiu Y, Liang Q. Non-uniform characteristics of solar flux distribution in the concentrating solar power systems and its corresponding solutions: A review. Chin Sci Bull. 2016;61:3208-37.

[22] Weinstein LA, Loomis J, Bhatia B, Bierman DM, Wang EN, Chen G. Concentrating Solar Power. Chem Rev. 
2015;115:12797-838.

[23] Wang K, He YL, Qiu Y, Zhang YW. A novel integrated simulation approach couples MCRT and Gebhart methods to simulate solar radiation transfer in a solar power tower system with a cavity receiver. Renew Energ. 2016;89:93-107.

[24] Abbas R, Martínez-Val JM. A comprehensive optical characterization of linear Fresnel collectors by means of an analytic study. Appl Energ. 2017;185:1136-51.

[25] Wang K, He YL, Cheng ZD. A design method and numerical study for a new type parabolic trough solar collector with uniform solar flux distribution. SCI CHINA SER E. 2014;57:531-40.

[26] Cheng ZD, He YL, Qiu Y. A detailed nonuniform thermal model of a parabolic trough solar receiver with two halves and two inactive ends. Renew Energ. 2015;74:139-47.

[27] Zheng ZJ, He Y, He YL, Wang K. Numerical optimization of catalyst configurations in a solar parabolic trough receiver-reactor with non-uniform heat flux. Sol Energ. 2015;122:113-25.

[28] Wang FQ, Tang ZX, Gong XT, Tan JY, Han HZ, Li BX. Heat transfer performance enhancement and thermal strain restrain of tube receiver for parabolic trough solar collector by using asymmetric outward convex corrugated tube. Energy. 2016;114:275-92.

[29] Zheng Z, Xu Y, He Y. Thermal analysis of a solar parabolic trough receiver tube with porous insert optimized by coupling genetic algorithm and CFD. SCI CHINA SER E. 2016;59:1475-85.

[30] Li L, Li Y, Sun J. Prospective fully-coupled multi-level analytical methodology for concentrated solar power plants: Applications. Appl Therm Eng. 2017;118:159-70.

[31] Wang F, Cheng Z, Tan J, Yuan Y, Shuai Y, Liu L. Progress in concentrated solar power technology with parabolic trough collector system: A comprehensive review. Renew Sust Energ Rev. 2017;79:1314-28.

[32] Zheng ZJ, Li MJ, He YL. Thermal analysis of solar central receiver tube with porous inserts and non-uniform heat flux. Appl Energ. 2017;185:1152-61.

[33] Du BC, He YL, Zheng ZJ, Cheng ZD. Analysis of thermal stress and fatigue fracture for the solar tower molten salt receiver. Appl Therm Eng. 2016;99:741-50.

[34] Besarati SM, Yogi Goswami D, Stefanakos EK. Optimal heliostat aiming strategy for uniform distribution of heat flux on the receiver of a solar power tower plant. Energ Convers Manag. 2014;84:234-43.

[35] Wang K, He YL. Thermodynamic analysis and optimization of a molten salt solar power tower integrated with a recompression supercritical $\mathrm{CO} 2$ Brayton cycle based on integrated modeling. Energ Convers Manag. 2017;135:336-50.

[36] Wang K, He YL, Zhu HH. Integration between supercritical CO 2 Brayton cycles and molten salt solar power towers: A review and a comprehensive comparison of different cycle layouts. Appl Energ. 2017;195:819-36.

[37] Zhu HH, Wang K, He YL. Thermodynamic analysis and comparison for different direct-heated supercritical CO2 Brayton cycles integrated into a solar thermal power tower system. Energy. 2017;DOI: https://doi.org/10.1016/j.energy.2017.08.067.

[38] Hafez AZ, Soliman A, El-Metwally KA, Ismail IM. Solar parabolic dish Stirling engine system design, simulation, and thermal analysis. Energ Convers Manag. 2016;126:60-75.

[39] Cui FQ, He YL, Cheng ZD, Li YS. Study on combined heat loss of a dish receiver with quartz glass cover. Appl Energ. 2013;112:690-6.

[40] Wang F, Guan Z, Tan J, Ma L, Yan Z, Tan H. Transient thermal performance response characteristics of porous-medium receiver heated by multi-dish concentrator. Int Commun Heat Mass. 2016;75:36-41.

[41] Balaji S, Reddy KS, Sundararajan T. Optical modelling and performance analysis of a solar LFR receiver system with parabolic and involute secondary reflectors. Appl Energ. 2016;179:1138-51.

[42] Sahoo SS, Singh S, Banerjee R. Steady state hydrothermal analysis of the absorber tubes used in Linear Fresnel 
Reflector solar thermal system. Sol Energ. 2013;87:84-95.

[43] Häberle A, Zahler C, de Lalaing J, Ven J, Sureda M, Graf W, et al. The Solarmundo Project. Advanced technology for solar thermal power generation. Solar World Congress. Adelaide, Australia 2001.

[44] Qiu Y, He YL, Cheng ZD, Wang K. Study on optical and thermal performance of a linear Fresnel solar reflector using molten salt as HTF with MCRT and FVM methods. Appl Energ. 2015;146:162-73.

[45] Craig KJ, Moghimi MA, Rungasamy AE, Marsberg J, Meyer JP. Finite-volume ray tracing using Computational Fluid Dynamics in linear focus CSP applications. Appl Energ. 2016;183:241-56.

[46] Grena R, Tarquini P. Solar linear Fresnel collector using molten nitrates as heat transfer fluid. Energy. 2011;36:1048-56.

[47] Mills DR, Morrison GL. Compact linear Fresnel reflector solar thermal powerplants. Sol Energ. 2000;68:263-83.

[48] Qiu Y, He YL, Wu M, Zheng ZJ. A comprehensive model for optical and thermal characterization of a linear Fresnel solar reflector with a trapezoidal cavity receiver. Renew Energ. 2016;97:129-44.

[49] Moghimi MA, Craig KJ, Meyer JP. A novel computational approach to combine the optical and thermal modelling of Linear Fresnel Collectors using the finite volume method. Sol Energ. 2015;116:407-27.

[50] Abbas R, Montes MJ, Piera M, Martínez-Val JM. Solar radiation concentration features in Linear Fresnel Reflector arrays. Energ Convers Manag. 2012;54:133-44.

[51] Abbas R, Montes MJ, Rovira A, Martínez-Val J. Parabolic trough collector or linear Fresnel collector? A comparison of optical features including thermal quality based on commercial solutions. Sol Energ. 2016;124:198-215.

[52] Montes MJ, Rubbia C, Abbas R, Martínez-Val JM. A comparative analysis of configurations of linear Fresnel collectors for concentrating solar power. Energy. 2014;73:192-203.

[53] Bellos E, Mathioulakis E, Tzivanidis C, Belessiotis V, Antonopoulos KA. Experimental and numerical investigation of a linear Fresnel solar collector with flat plate receiver. Energ Convers Manag. 2016;130:44-59.

[54] Li L, Sun J, Li YS. Thermal load and bending analysis of heat collection element of direct-steam-generation parabolic-trough solar power plant. Appl Therm Eng. 2017;DOI: https://doi.org/10.1016/j.applthermaleng.2017.08.129.

[55] Lu J, Yuan Q, Ding J, Wang W, Liang J. Experimental studies on nonuniform heat transfer and deformation performances for trough solar receiver. Appl Therm Eng. 2016;109:497-506.

[56] Kutscher C, Mehos M, Turchi C, Glatzmaier G, Moss T. Line-focus solar power plant cost reduction plan (Milestone Report). National Renewable Energy Laboratory (NREL), Golden, CO.; 2010.

[57] Qiu Y, Li MJ, He YL, Tao WQ. Thermal performance analysis of a parabolic trough solar collector using supercritical CO2 as heat transfer fluid under non-uniform solar flux. Appl Therm Eng. 2017;115:1255-65.

[58] Dey CJ. Heat transfer aspects of an elevated linear absorber. Sol Energ. 2004;76:243-9.

[59] Eck M, Uhlig R, Mertins M, Häberle A, Lerchenmüller H. Thermal Load of Direct Steam-Generating Absorber Tubes with Large Diameter in Horizontal Linear Fresnel Collectors. Heat Transfer Eng. 2007;28:42-8.

[60] Abbas R, Muñoz-Antón J, Valdés M, Martínez-Val JM. High concentration linear Fresnel reflectors. Energ Convers Manag. 2013;72:60-8.

[61] Serrano-Aguilera JJ, Valenzuela L, Parras L. Thermal 3D model for direct solar steam generation under superheated conditions. Appl Energ. 2014;132:370-82.

[62] Oommen R, Jayaraman S. Development and performance analysis of compound parabolic solar concentrators with reduced gap losses-oversized reflector. Energ Convers Manag. 2001;42:1379-99.

[63] He YL, Xiao J, Cheng ZD, Tao YB. A MCRT and FVM coupled simulation method for energy conversion process in parabolic trough solar collector. Renew Energ. 2011;36:976-85.

[64] Cheng ZD, He YL, Cui FQ, Du BC, Zheng ZJ, Xu Y. Comparative and sensitive analysis for parabolic trough solar 
collectors with a detailed Monte Carlo ray-tracing optical model. Appl Energ. 2014;115:559-72.

[65] Qiu Y, He YL, Li PW, Du BC. A comprehensive model for analysis of real-time optical performance of a solar power tower with a multi-tube cavity receiver. Appl Energ. 2017;185:589-603.

[66] Xu Y, Cui K, Liu D. The development of a software for solar radiation and its verification by the measurement results on the spot. Energ Tech. 2002;26:237-9.

[67] Holland JH. Adaptation in natural and artificial systems: an introductory analysis with applications to biology, control, and artificial intelligence. Michigan: The University of Michigan Press; 1975.

[68] Xi H, Li MJ, He YL, Zhang YW. Economical evaluation and optimization of organic Rankine cycle with mixture working fluids using R245fa as flame retardant. Appl Therm Eng. 2017;113:1056-70.

[69] Xi H, Li MJ, Xu C, He YL. Parametric optimization of regenerative organic Rankine cycle (ORC) for low grade waste heat recovery using genetic algorithm. Energy. 2013;58:473-82.

[70] Xi H, Li MJ, He YL, Tao WQ. A graphical criterion for working fluid selection and thermodynamic system comparison in waste heat recovery. Appl Therm Eng. 2015;89:772-82.

[71] Wang K, He YL, Xue XD, Du BC. Multi-objective optimization of the aiming strategy for the solar power tower with a cavity receiver by using the non-dominated sorting genetic algorithm. Appl Energ. 2017;205:399-416.

[72] Deb K, Pratap A, Agarwal S, Meyarivan T. A fast and elitist multiobjective genetic algorithm: NSGA-II. Ieee T Evolut Comput. 2002;6:182-97.

[73] Tzeng GH, Huang JJ. Multiple attribute decision making: methods and applications. Boca Raton: CRC press; 2011.

[74] Chemisana D, Barrau J, Rosell JI, Abdel-Mesih B, Souliotis M, Badia F. Optical performance of solar reflective concentrators: A simple method for optical assessment. Renew Energ. 2013;57:120-9.

[75] Wendelin T. SolTrace: a new optical modeling tool for concentrating solar optics. ASME 2003 Int Sol Energy Conf. Kohala Coast, Hawaii: American Society of Mechanical Engineers; 2003. 253-60. 